\title{
Genome-wide identification and analysis of Oleosin gene family in four cotton species and its involvement in oil accumulation and germination
}

\author{
Yanchao Yuan ${ }^{1 \dagger}$, Xinzhe Cao ${ }^{1 \dagger}$, Haijun Zhang ${ }^{2 \dagger}$, Chunying Liu ${ }^{1}$, Yuxi Zhang ${ }^{1}$, Xian-Liang Song ${ }^{2^{*}}$ and \\ Shupeng Gai ${ }^{*}$
}

\begin{abstract}
Background: Cotton is not only a major textile fiber crop but also a vital oilseed, industrial, and forage crop. Oleosins are the structural proteins of oil bodies, influencing their size and the oil content in seeds. In addition, the degradation of oleosins is involved in the mobilization of lipid and oil bodies during seed germination. However, comprehensive identification and the systematic analysis of the Oleosin gene (OLEOS) family have not been conducted in cotton.

Results: An in-depth analysis has enabled us to identify 25 and 24 OLEOs in tetraploid cotton species G. hirsutum and G. barbadense, respectively, while 12 and 13 OLEOs were identified in diploid species G. arboreum and G. raimondii, respectively. The 74 OLEOs were further clustered into three lineages according to the phylogenetic tree. Synteny analysis revealed that most of the OLEOs were conserved and that WGD or segmental duplications might drive their expansion. The transmembrane helices in GhOLEO proteins were predicted, and three transmembrane models were summarized, in which two were newly proposed. A total of 24 candidate miRNAs targeting GhOLEOs were predicted. Three highly expressed oil-related OLEOs, GH_A07G0501 (SL), GH_D10G0941 (SH), and GH_D01G1686 (U), were cloned, and their subcellular localization and function were analyzed. Their overexpression in Arabidopsis increased seed oil content and decreased seed germination rates.
\end{abstract}

Conclusion: We identified OLEO gene family in four cotton species and performed comparative analyses of their relationships, conserved structure, synteny, and gene duplication. The subcellular localization and function of three highly expressed oil-related OLEOs were detected. These results lay the foundation for further functional characterization of OLEOs and improving seed oil content.

Keywords: Cotton, Oleosin, Gene family, Gene identification, Fatty acid, Seed germination

*Correspondence: songx1999@163.com; spgai@qau.edu.cn

†Yanchao Yuan, Xinzhe Cao and Haijun Zhang contributed equally to this work.

${ }^{1}$ College of Life Sciences, Qingdao Agricultural University, Key Lab of Plant Biotechnology in Universities of Shandong Province, Qingdao, China

${ }^{2}$ State Key Laboratory of Crop Biology/Agronomy College, Shandong Agricultural University, Taian, Shandong, China

\section{Background}

Cotton (Gossypium. spp.) seed is the sixth-largest vegetable oil resource globally and the renewable raw materials for biofuel and industrial products, such as hydraulic oils and lubricants [1]. The demand for biodiesel is growing, whereas cottonseed oil accounts for only $17-27 \%$ of seed weight [2]. Therefore, increasing the oil content becomes an important target for cotton 
breeding. Nowadays, genes related to lipid biosynthesis have been studied extensively. Thus, the homology genes involved in the lipid storage or metabolism pathway should be analyzed to understand functional differentiation.

The seed lipids are mainly stored as triacylglycerols (TAGs) in oil bodies (OBs), which are lipid storage organelles and are widely distributed in lipid storage cells [3]. The oil body is approximately $0.5-2 \mu \mathrm{m}$ in diameter and has the basic structure that a core of neutral lipids surrounded by the phospholipid monolayer with specific proteins [4]. It is well known that the OBs are synthesized in the endoplasmic reticulum (ER) and then budded to the cytoplasm $[4,5]$. The specific proteins in oil bodies, mainly oleosin, caleosin, and steroleosin, have been shown to play an essential role in regulating oil body size and number and lipid accumulation [5, 6]. Among them, oleosins account for $80-90 \%$ of the structural proteins in OBs and play a key role in lipid storage [7]. The Oleosin $(O L E O)$ gene sequence was first identified and characterized in maize [8] and then cloned in various plants, including rapeseed [9], sesame [10], soybean [11], rice [12], sunflower [13].

OLEOs from diverse plants can be divided into six lineages (M, T, P, U, SL, and SH) [14]. The M (Mesocarp) lineage exists in the Lauraceae, and the $\mathrm{T}$ (Tapetum) is only identified in the Tapeta of Brassicaceae. The P (Primitive) lineage was mainly distributed in green algae, which might be the origin of the $U$ (Universal) lineage detected in all terrestrial plants, and further evolved to SL (Seed low-molecular-weight) and SH (Seed high-molecularweight) lineages [14-16]. In Arabidopsis thaliana, 17 OLEOs were identified, including nine of $\mathrm{T}$, three of $\mathrm{U}$, two of SL, and three of SH [17].

Oleosin peptides can be divided into three domains: a central hydrophobic domain (72 residues), an $\mathrm{N}$-terminal amphiphilic region (50-70 residues), and a C-terminal amphiphilic region (variable length). The central hydrophobic domain is a highly conserved hairpin structure that can insert into the phospholipid membrane and plays an essential role in targeting and stabilizing the oil body [18]. The loop of the hairpin is a proline junction ( $\mathrm{PX}_{5} \mathrm{SPX}_{3} \mathrm{P}, \mathrm{X}$ representing a large nonpolar residue), in which the Pro and Ser residues are highly conserved in various plants. The replacement of Pro residue can lead to abnormal targeting of the OB [19]. The $\mathrm{N}$ - and C-terminal amphiphilic domains, located on the surface of the oil body, can not only maintain the size of the OB through their steric hindrance and electronegative repulsion [20] but also regulate the $\mathrm{OB}$ by combining it with metabolic enzymes and regulatory proteins [21-23]. Take together, oleosins are involved in the oil bodies regulation and biosynthesis, and metabolism of lipid [24, 25].
As lipid storage organelles, the number and size of oil bodies are partly related to the oil content of seeds, and high-oil seeds tend to have more oil bodies [26]. Furthermore, many previous studies showed that oleosins affect the size and number of seed oil bodies and regulate the oil content [17, 27-31]. In the middle stage of seed development, the lack of oleosins caused oil body fusion, leading to larger oil bodies and the decrease of oil content [7, 32]. Similar results showed that the overexpression of OLEO1 and OLEO4 was found to reduce the size of oil bodies in A. thaliana seeds [33]. Additionally, the overexpression of GmOLEO1 increased the number of oil bodies and oil accumulation, whereas the $\mathrm{OB}$ size decreased [31]. Moreover, co-expression of OLEOs and the genes involved in TAG biosynthesis increased lipid production [34], which might be a new method to enhance oil content more efficiently.

It is also reported that the OLEOs could be induced by water stress, jasmonic acid, ABA, and osmotic stabilizer [35], indicating that OLEOs might play an essential role in engineering salt, cold, and drought tolerance in plants. Shimada et al. (2008) found that the OLEOs could maintain the germination rate (GR) of Arabidopsis seeds and improve their overwintering viability by inhibiting the oil body fusion. In addition, OLEOs were also involved in heat-shock in embryogenic carrot cell lines [36] and induced by $\mathrm{ABA}$, salt, and PEG in sorghum, suggesting that oleosin proteins could regulate the stability and permeability of the membrane [37].

Oleosins have been widely studied nowadays, whereas little attention has been paid to the OLEO gene family in critical oil crops. In the current study, the oleosins from the four cotton species, G. arboreum, G. raimondii, G. barbadense, and G. hirsutum, were identified. Their features, including gene structure, conserved motifs and domain, chromosomal location, evolution, subcellular, synteny relationship, and expression patterns, were analyzed and characterized. In addition, the transmembrane helices in GhOLEO proteins were predicted and summarized into three transmembrane models. Subsequently, some GhOLEOs preferentially expressed in ovules were cloned and transformed into Arabidopsis. The overexpression of OLEOs promoted the accumulation of lipid in Arabidopsis seeds and decreased seed germination rates. Overall, these results provide a foundation for further understanding the function of oleosins in cotton.

\section{Results}

Whole-genome identification and characterization of Oleosin genes in four cotton species

Combined with the results of BLASTP search, HMMER analysis, and CDD check, a total of $25,24,12$, and 13 Oleosins were identified in two tetraploids, G. hirsutum 
and G. barbadense, and two diploids, G. arboreum and G. raimondii, respectively. The gene ID, physical location, and other features of these Oleosins were listed in Table S1. The number of amino acids (NAA), molecular weight $(\mathrm{Mw})$, and isoelectric point $(\mathrm{pI})$ of oleosin proteins varied from 116 to $237,12.30 \mathrm{kDa}$ to $26.47 \mathrm{kDa}$, and 8.48 to 10.97 in G. arboreum, respectively. Those were 116 to 237 , $12.42 \mathrm{kDa}$ to $26.55 \mathrm{kDa}$, and 8.72 to 11.30 in G. raimondii, respectively, and similar to G. arboreum. In addition, the NAA, Mw, and $\mathrm{pI}$ of oleosin proteins in A-genomes of G. hirsutum were $116-175,12.33-18.49 \mathrm{kDa}$, and 9.36 10.97, respectively, which were similar to those of oleosin proteins in A-genomes of G. barbadense, with the value ranges were $116-175,12.33-18.54 \mathrm{kDa}$, and 9.36-10.97, respectively. The NAA, Mw, and $\mathrm{pI}$ of oleosin proteins in the D-genomes of G. hirsutum were also similar to those in the D-genomes of G. barbadense. In contrast, those characters of diploids (G. arboreum and G. raimondii) were not similar to tetraploids (G. hirsutum and G. barbadense), which mainly were caused by Ga02G0988 and Gorai.002G174000. These results suggested that two diploids might be subjected to one same or similar environmental pressure. In contrast, two tetraploids might be subjected to another similar selection pressure.

The number of OLEOs in the A- and D-genomes is nearly equal in all four cotton species. The OLEO numbers in the A-genome of G. arboreum, G. hirsutum, and G. barbadense were all 12, while that in the D-genome of G. raimondii, G. hirsutum, and G. barbadense were 13, 13, and 12, respectively. As shown in Fig. S1, there were two OLEOs on each Chr05/A05/D05 and Chr09/A09/ D09, and one OLEO on each Chr06/A06/D06, Chr10/ A10/D10, Chr11/A11/D11, Chr12/A12/D12, and Chr13/ A13/D13, in G. arboreum/G. hirsutum/G. barbadense respectively. It was different that one and three Oleosins were in Chr02 and Chr07 of G. arboreum, respectively, while one and two Oleosins in A01/D01 and A07/D07 of G. hirsutum and G. barbadense, respectively. These results indicated that Oleosins had a similar distribution on chromosomes in G. arboreum, G. hirsutum, and G. barbadense. Moreover, the OLEOs in G. raimondii were located in chromosome Chr01, Chr02, Chr06, Chr07, Chr08, Chr09, Chr10, Chr11, and Chr13 with numbers were three, one, two, one, one, two, one, one, and one, respectively. The OLEO distributions on chromosomes in G. raimondii were different from the other three species. These results were in agreement with those of predecessors that A-genome of G. arboreum and G. hirsutum originate from a common ancestor $\mathrm{A} 0$ [38], and the nascent allotetraploid, which originated from hybridization of an A- and D-genome-like species, diverged into five cotton species, including G. barbadense and G. hirsutum [39-41].

\section{Phylogenetic analysis of Oleosin genes in four cotton species}

To study the phylogeny and subgroups of the OLEO family, a phylogenetic tree was constructed by all oleosin protein sequences in four cotton species combined with 17 A. thaliana and 48 B. napus oleosin proteins (Fig. 1). In the phylogenetic tree, the cotton OLEOs were divided into three lineages ( $\mathrm{SH}, \mathrm{SL}$, and $\mathrm{U}$ ) without $\mathrm{T}$ lineages, which were only founded in the Tapeta of Brassicaceae [14]. In detail, the four species had the same number of each subclass of oleosins per haploid genome with the exception of SL class, for which there were three copies in $G$ barbadense and G. arboretum, but four copies in G. raimondii and the D genome of G. hirsutum (Fig. 1). Furthermore, two genes from each tetraploid species and one gene from each diploid species cluster together in each branch of the phylogenetic tree, except Gorai.001G024800 and GH_D07G0260 in SL. The two genes from each tetraploid species in each branch were one A-genome and one $\mathrm{D}$-genome gene. This might be due to the fact that tetraploid is derived from two diploids [42] or that the subgenomes of tetraploids and diploids are derived from the same ancestors [38].

\section{Synteny and duplication analysis of Oleosin genes}

To show the synteny relationships, the whole genomes and all the homologous OLEOs of the four cotton species were aligned and analyzed (Table S2; Fig. S2). Of all the 25 GhOLEOs, 23, 24, and 25 had homologous OLEOs in G. arboreum, G. raimondii, and G. barbadense, respectively, and 23 GhOLEOs were the common homologous genes in the other three cotton species.

During Gossypium evolution, the duplicate mechanisms, including tandem, proximal and dispersed duplications, and WGD (whole-genome duplications) or segmental duplications, play an important role in the expansion of gene families [43, 44]. In the tetraploid kinds of cotton (G. hirsutum and G. barbadense), the duplications of OLEOs were all categorized as WGD or segmental duplications (Table S3). However, in the diploids, three GaOLEOs (Ga05G2701, Ga07G0528, and Ga13G1629) and four GrOLEOs (Gorai.001G051400, Gorai.009G267600, Gorai.011G094900, and Gorai.013G149000) were considered as dispersed duplications, while the others were all the WGD or segmental duplications. Therefore, the expansion and evolution of the $O L E O$ gene family in cotton might be mainly driven by WGD or segmental duplications.

For understanding the collinear relationships of all the cotton $O L E O$ genes among the two tetraploids and two diploids, the linked gene pairs were all identified (Fig. S2 and Fig. 2). Corresponding to G. arboreum, there were 16 


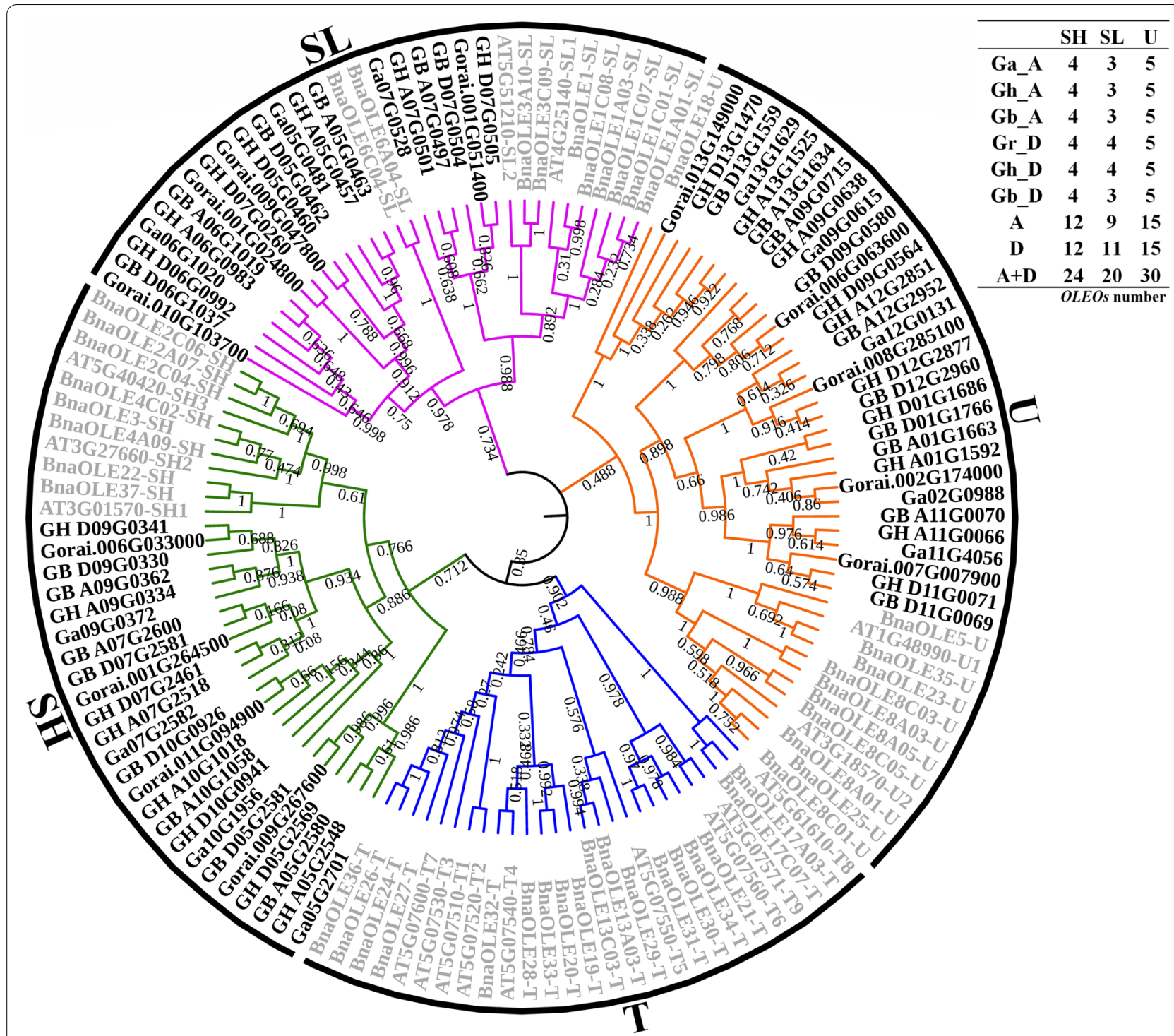

Fig. 1 Phylogenetic tree of Oleosin genes from four cotton species, Arabidopsis and Brassica napus. The bootstrap values from 0.08 to 1 were shown on the branch lines

and 17 collinear gene pairs identified in the A-genomes of G. hirsutum and G. barbadense, respectively, and 19 and 18 pairs were identified in the D-genomes of G. hirsutum and G. barbadense, respectively. In addition, corresponding to G. raimondii, 15 and 15 collinear gene pairs were identified in the A-genomes of G. hirsutum and G. barbadense, respectively, and 19 and 18 pairs were in the D-genomes of G. hirsutum and G. barbadense, respectively. Furthermore, the gene pairs number between tetraploid A-genomes and diploid genomes were approximate, and the same between tetraploid D-genomes and diploid genomes.

\section{Gene structure and conserved motif analysis of Oleosin genes}

Based on the gene annotation gff3 files, the gene structure of $O L E O$ genes was analyzed and showed in Fig. 3. Results showed that the great majority of the OLEO genes had only one exon, and 11 genes contained two exons and one intron. Furthermore, the genes in the branch of the same subfamily contained similar gene structures such as intron/exon number and intron/ exon length. In addition, ten of thirteen OLEO genes in G. raimondii had the untranslated regions (UTRs), and there were no UTRs in OLEOs of the applied genome versions of G. arboreum, 


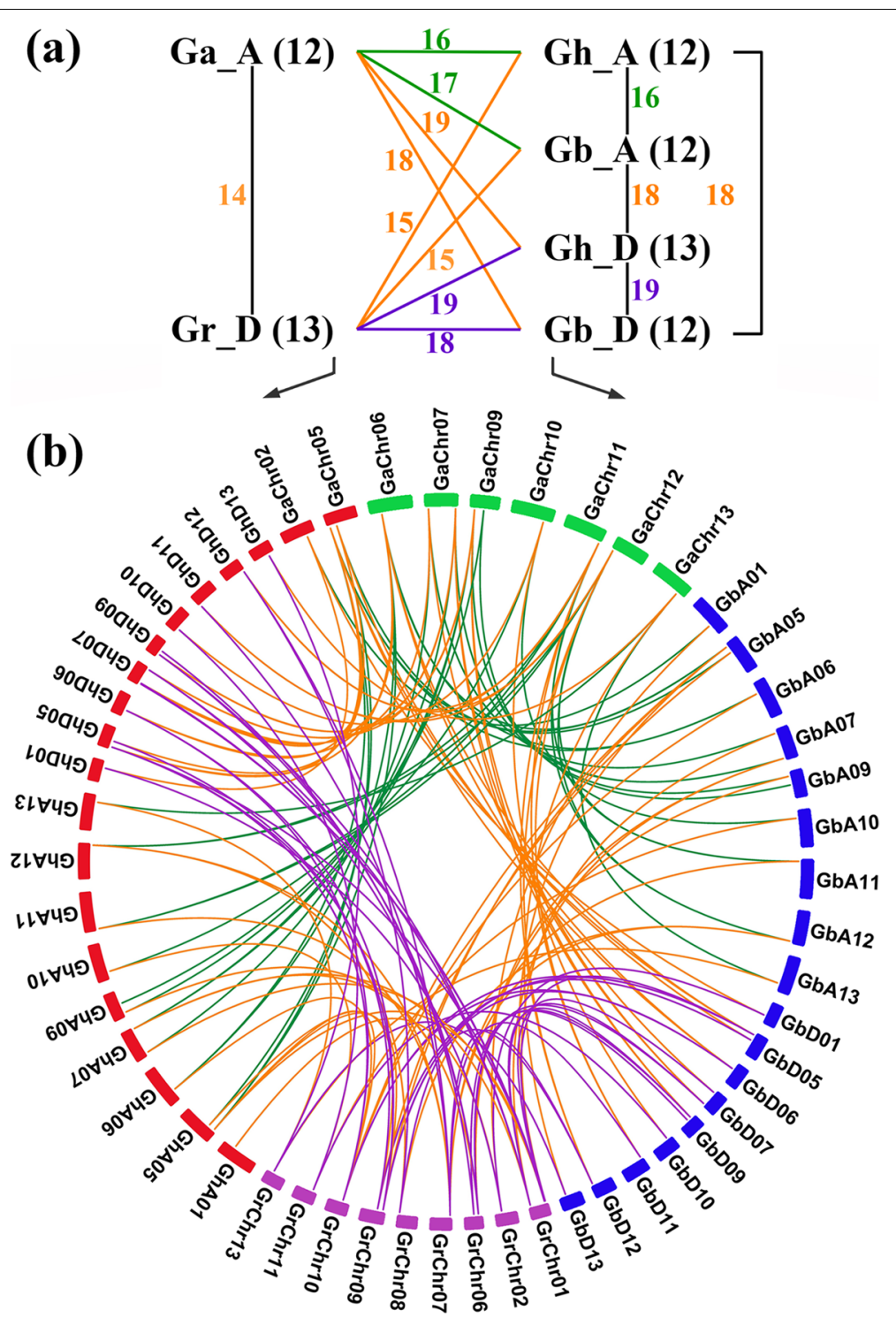

Fig. 2 Synteny of Oleosin genes among G. hirsutum, G. barbadense, G. arboretum and G. raimondii. a The number of collinear gene pairs among the four cotton cultivars. b Visualization of Oleosin genes synteny

G. hirsutum and G. barbadense in this study, because their gff3 files had no UTR annotations.

The conserved motifs were analyzed with the fulllength oleosin protein sequences submitted to MEME web-server. As shown in Fig. 3 and Table S4, 24 conserved motifs with 6 - 50 amino acids were identified in $O L E O$ genes. The number of conserved motifs in OLEO genes ranged from three to nine, and only one gene had three motifs, and two genes had four motifs. Motif 1- 6 were all founded in the $\mathrm{SH}, \mathrm{SL}$, and $\mathrm{U} O L E O s$. Motif 1 , which containing proline junction $\left(\mathrm{PX}_{5} \mathrm{SPX}_{3} \mathrm{P}\right)$, was common to almost all OLEO genes, and only one gene, GB_A09G0715, did not contain motif 1 but had a proline junction. Following motif 1 , motif 2 and motif 3 were conserved in 68 and 63 OLEOs, respectively. Thus, the number and type of conserved motifs were similar in the same branch of the evolutionary tree, and some motifs were specific to subfamilies. For example, motifs 10, 15, $17,18,19,21$, and 24 were specific to subfamily $U$, while motifs $7,12,13,16,20,22$, and 23 were exclusively in $\mathrm{SH}$ subfamily members. These indicated that the proteins in different subfamilies had different conserved motif distributions, which might provide a reference for studying the functional differentiation between subfamilies. In the same subfamily, the conserved motifs distribution and gene structure were similar. They proved the accuracy 


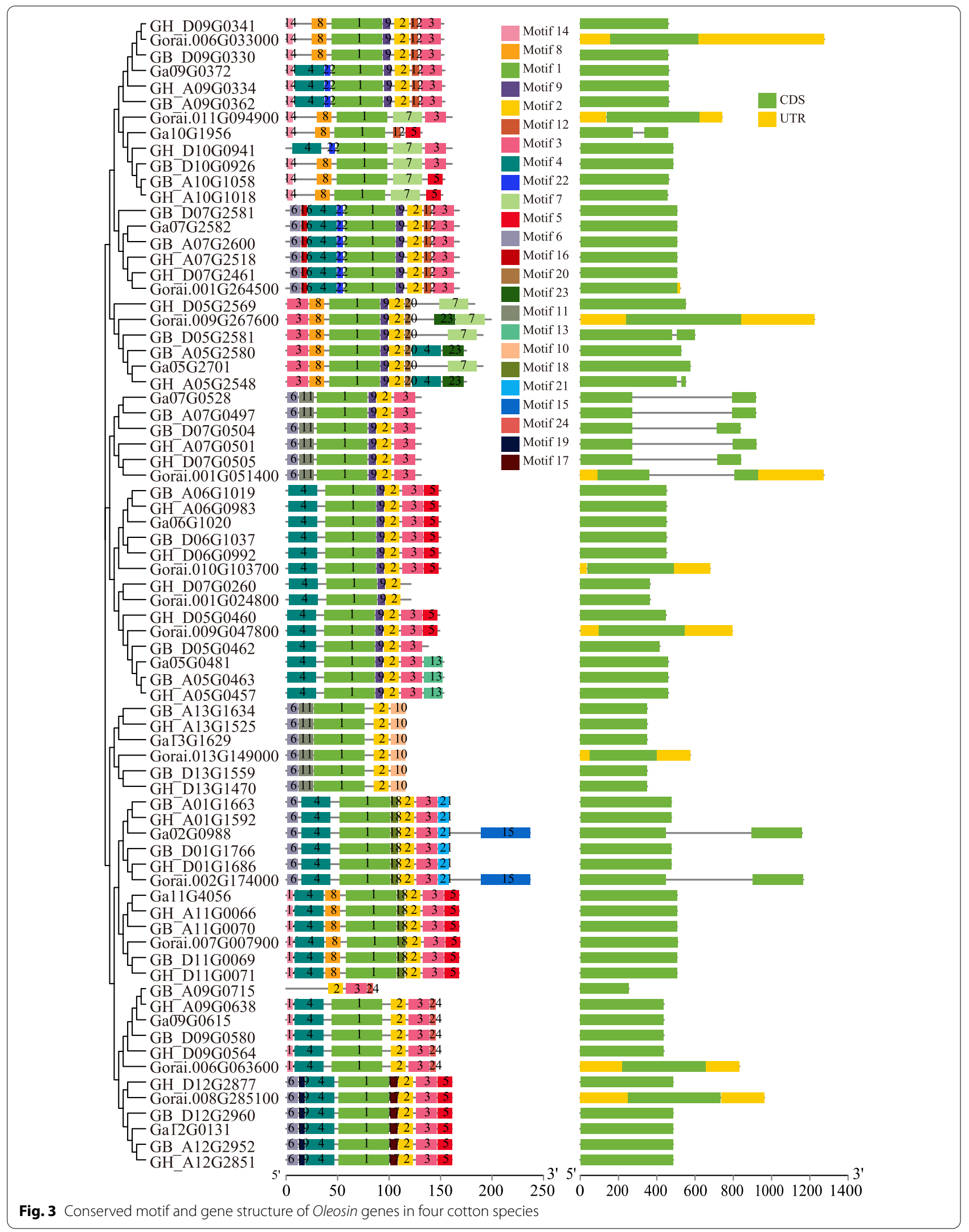


of the evolutionary tree constructed in this study from another aspect.

\section{The miRNA targeting GhOLEO genes}

To dissect the regulation of GhOLEO expression, the candidate miRNAs targeting the GhOLEOs were predicted using the psRNATarget server with the miRNAs in PMRD, miRbase, and psRNATarget databases and published miRNAs in G. hirsutum. With expectations lower than 4.5, 24 miRNAs targeting 14 GhOLEOs were identified (Fig. 4), and their details are shown in Table S5 [45]. MiRNAs and their targeted GhOLEOs were not one-to-one correspondence, and many miRNA targeted to a common GhOLEO or one miRNA had several targets. For example, GH_D01G1686 was co-targeted by ghr-miR482d.2 and ghr-miR8672g, and ghr-miR418 could suppress GH_A05G0457 and GH_D05G0460. Among the 24 miRNAs, 12 (ghr-miR159b, ghr-miR160a,
ghr-miR168.1, ghr-miR3627b, ghr-miR418, ghr-miR479, ghr-miR482d.2, ghr-miR7507, ghr-miR825, ghrmiR8672b, ghr-miR8672g, and $g h r-m i R 8672 h)$ belonged to the verified miRNA families, while others were newly discovered in the listed references (Table S6 [45-52]). In addition, five, four, and five of the GhOLEOs targeted by miRNA were the members of U, SL, and SH lineages, respectively.

\section{Expression profile analysis of Oleosin genes}

Based on the gene expression database of TM-1 and H7124 [53], the expression profiles of OLEOs in root, stem, leaf, and ovules $(0,1,3,5,10,20 \mathrm{dpa})$ were normalized to $\log 2^{\mathrm{FPKM}}$ and performed with heatmap (Fig. 5; Table S7). As shown, the gene expression pattern was similar between the homologous GhOLEOs and GbOLEOs. Moreover, most genes were preferentially expressed in ovules, especially in ovules of 10 and $20 \mathrm{dpa}$,

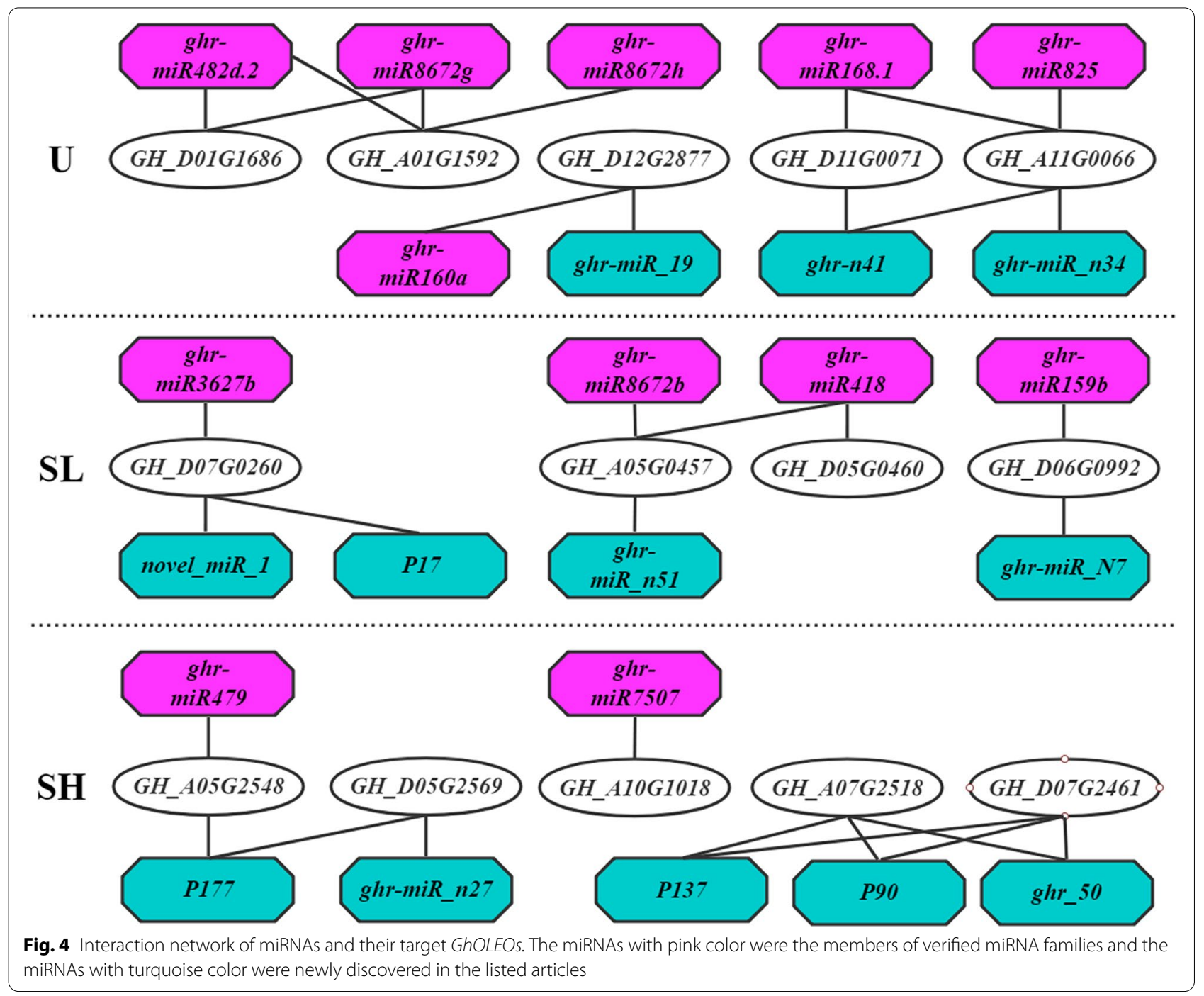




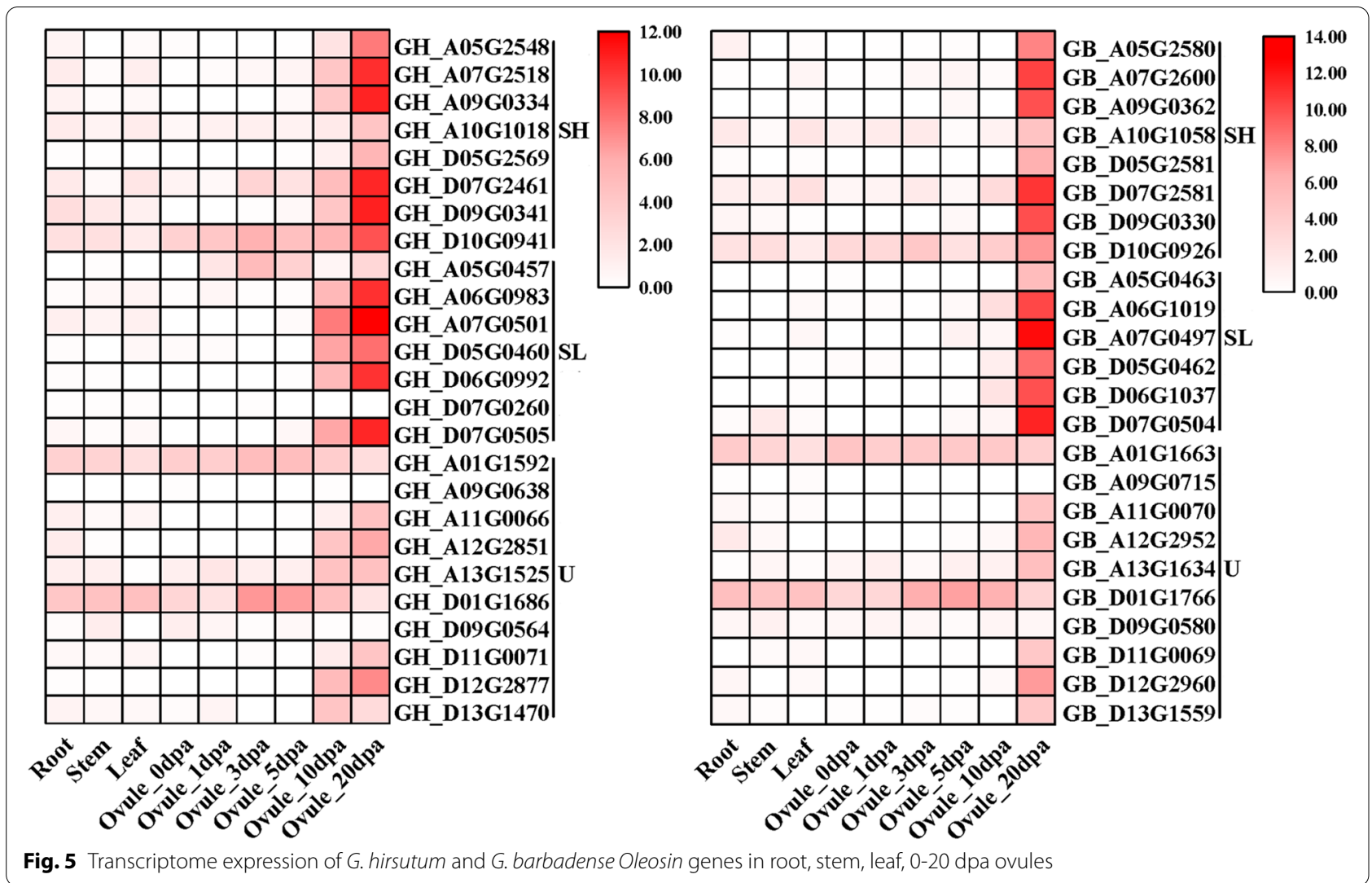

indicating that these $O L E O$ genes might be related to oil composition in cotton. In addition, the expression of the $\mathrm{SL}$ and $\mathrm{SH} O L E O s$ was higher than $\mathrm{U}$ OLEOs in ovules. In order to confirm the expression pattern of OLEOs in ovules, six GhOLEO genes with relatively high FPKM expression were further analyzed using qRT-PCR and displayed in Fig. 6. The expression pattern of these genes in $\mathrm{qRT}$-PCR was very consistent with those in the heatmap. The results showed that three SH OLEOs and two SL OLEOs were highly expressed in $20 \mathrm{dpa}$ and $25 \mathrm{dpa}$ ovules, while GH_D01G1686(U) was highly expressed in 1-10 dpa ovules.

\section{Subcellular localization and transmembrane helices analysis of Oleosins}

With prediction online, all the OLEO proteins in four cotton species were preliminary positioned in plasmamembrane (Table S1). To further determine the subcellular localization of GhOLEOs, one gene with relatively high expression at all stages was screened from SL, SH, and $U$. These three genes cloned from cDNA of ovules were used for constructing the GFP fusion protein. The recombinant vectors (GH_D01G1686:GFP, GH_ A07G0501:GFP, and GH_D10G0941:GFP) were transformed into tobacco leaves, respectively, mediated by $A$. tumefaciens (EHA105). The leaves were incubated in Nile red and then were checked by monitoring the GFP signal. The lipid drops could be stained red with Nile red, and GFP proteins emit green light under excitation conditions, as shown in Fig. 7. And, the results showed that the yellow fluorescent signals, which was the composite light of green (GFP) and red (Nile red), were present in the membrane of oil bodies in the merged fields of the three fusion proteins (Fig. 7), indicating that the SL, SH, and $U$ oleosin protein might be located on the oil body membrane (plasmamembrane).

For further understanding of the transmembrane helices characters, the GhOLEO protein sequences were submitted and analyzed in TMHMM Server v. 2.0 online. All the GhOLEO proteins could be categorized into three models, including $\mathrm{nC}$ ( $\mathrm{N}$-terminus inside and $\mathrm{C}$-terminus outside), $\mathrm{Nc}$ ( $\mathrm{N}$-terminus outside and $\mathrm{C}$-terminus inside), and $\mathrm{NC}$ (both $\mathrm{N}$-terminus and $\mathrm{C}$-terminus outside), based on the transmembrane characters (Fig. 8, Fig. S3, Fig. S4, and Fig. S5). All the $\mathrm{nC}$ and Nc proteins had three transmembrane helices, and one terminus $(\mathrm{N}$ - or C-terminus) was sticking out into the cytoplasm, while $\mathrm{NC}$ proteins had two transmembrane helices and both $\mathrm{N}$ and C-terminus were in the cytoplasm. In SH GhOLEO proteins, only one was $\mathrm{nC}$, and the others were Nc (Fig. 


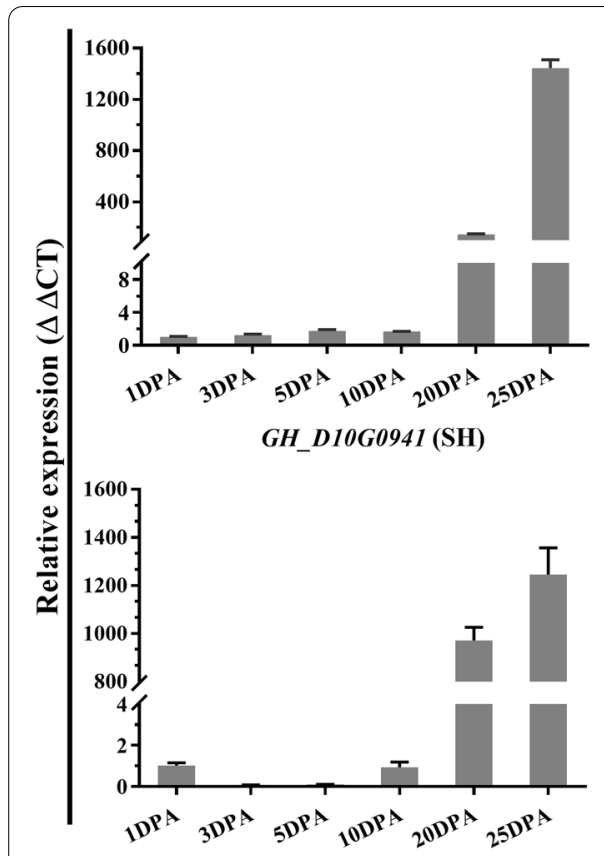

GH_A07G0501 (SL)

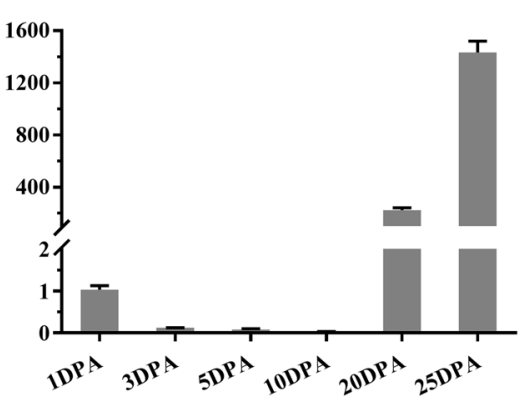

GH_D09G0341 (SH)

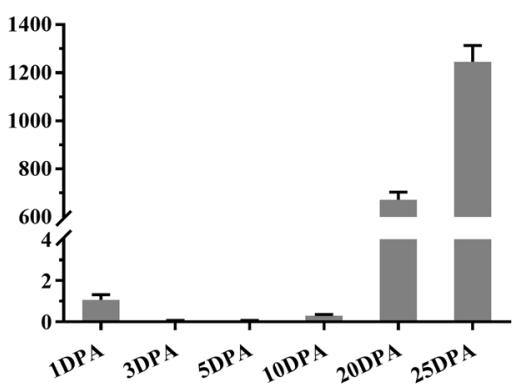

GH_D07G0505 (SL)

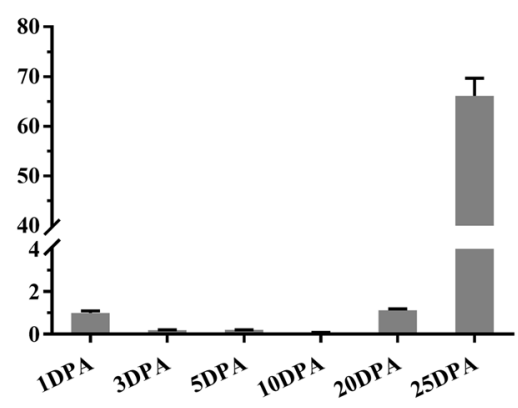

GH_A10G1018 (SH)

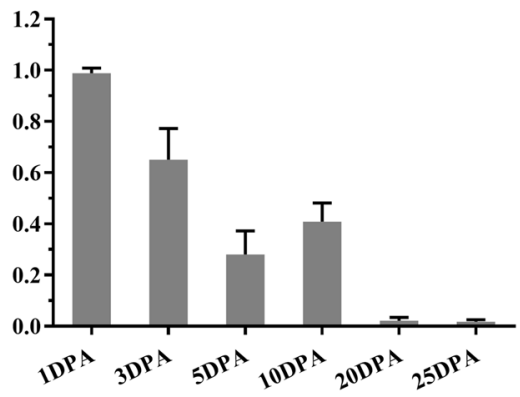

GH D01G1686 (U)

Fig. 6 The expression levels of four GhOLEOs in $1 \mathrm{dpa}, 3 \mathrm{dpa}, 5 \mathrm{dpa}, 10 \mathrm{dpa}, 20 \mathrm{dpa}$, and $25 \mathrm{dpa}$ ovules of G. hirsutum were performed with qRT-PCR. Each column of the bar chart shows the average value of three repeats, and each error bar represents one standard error

S3), while all the SL GhOLEOs belonged to NC (Fig. S4). Furthermore, all three models appeared in the U GhOLEOs (Fig. S5).

\section{Ectopic overexpression of GhOLEOs increased seed oil content in Arabidopsis}

Three GhOLEOs, GH_A07G0501 (SL), GH_D10G0941 (SH), and GH_D01G1686 (U), were cloned into vector pCAMbia2300 with 35S promoter, and the reconstructed and empty vectors were transformed into Col-0 plants. The overexpression lines (OE) and empty vector lines (CT) were selected and bred to T3 generation. Then, the expression levels of GhOLEOs in CT and T3 lines were analyzed by qRT-PCR (Fig. 9A). Based on their expression levels, the OE1, OE4, and OE8 of GH_A07G0501, the OE1, OE3, and OE5 of GH_D10G0941, and OE1, OE3, and OE5 of GH_D01G1686 were employed to detect the average contents of seed fatty acid using GC-MS, and the CT lines were used as control. As shown, all the fatty acid components and their total content in seeds of GH_A07G0501 and GH_D01G1686 transgenic lines were significantly higher than CK lines except that 22:1 fatty acid in $G H \_D 01 G 1686$ OE lines was not significantly increased (Fig. 9B). In GH_D10G0941 transgenic lines, partial fatty acid components and the total fatty acid content were significantly increased. Moreover, in the incremental contents, the unsaturated fatty acids were
5.04 5.97 times more than saturated, and the polyunsaturated were nearly twice monounsaturated fatty acids (Table 1). These results suggested that $\mathrm{SL}, \mathrm{SH}$, and $\mathrm{U}$ Oleosins could promote the accumulation of fatty acids in seeds, and their contribution to unsaturated fatty acids was higher than saturated fatty acids.

\section{GhOLEOs decrease the germination rates of seeds}

As is known, fatty acids play an important role in the resistance of plants to stress, such as chilling, salt, and drought. Moreover, the lipids could provide the seeds with energy to survive adverse conditions. Previous research suggested that oleosin, maintaining seed oil content and oil body size, was essential in the resistance of seeds to freezing $[54,55]$. So, we asked whether the oleosin could increase the resistance of seeds to salt and chilling. For this, the germination rates (GR) of the OE lines selected above and the $\mathrm{CT}$ lines were determined under control, $150 \mathrm{mM} \mathrm{NaCl}$, and $4{ }^{\circ} \mathrm{C}$ conditions, respectively. The results showed that the GRs of CT and OE lines performed better under control conditions than at $150 \mathrm{mM}$ $\mathrm{NaCl}$ and $4{ }^{\circ} \mathrm{C}$. The GRs of CT, OE-GH_D10G0941 (SH), OE-GH_D01G1686 (U), and OE-GH_A07G0501 (SL) were successively from high to low in all conditions (Fig. 10). These results indicated that the overexpression of GhOLEOs decreases the germination rates of seeds and the resistance to salt and chilling. 


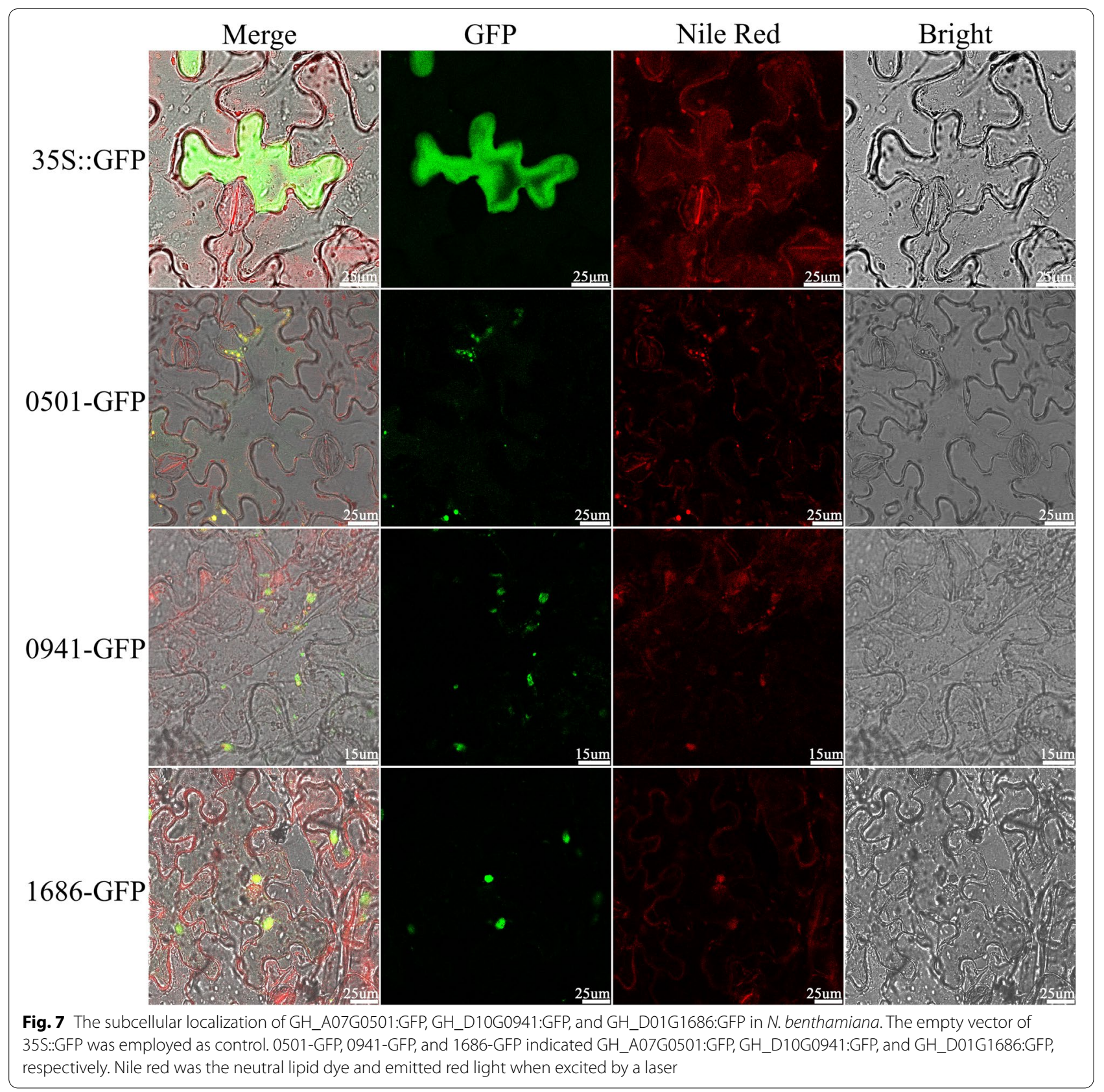

\section{Discussion}

The $O L E O$ gene family has been whole-genome screened and characterized in several plants, including Coffea canephora [56], Brassica napus L [17], and Carthamus tinctorius L [57]. Their functions were also widely studied in many plant species with cloning and overexpression [31,33]. It is generally accepted that oleosins play an essential role in $\mathrm{OB}$ regulation and lipid accumulation [17, 27-31]. However, it is paid little attention to the oleosins in cotton, which is also a critical oil crop. Nowadays, the genomes of G. hirsutum, G. barbadense, G. arboreum, and G. raimondii have been better sequenced further to understand cotton genomics and genetics [53, $58,59]$. With this, the members of the OLEO gene family and their evolutionary relationships might be further explored and determined in cotton.

In this study, a total of 25, 24, 12, and 13 OLEOs were identified in G. hirsutum, G. barbadense, G. arboreum, and G. raimondii, respectively (Table $\mathrm{S} 1$ ). In the previous studies, OLEOs had been clustered into six lineages $(\mathrm{M}$, $\mathrm{T}, \mathrm{P}, \mathrm{U}, \mathrm{SL}$, and $\mathrm{SH}$ ) with the alignment of about 1000 oleosin sequences in 22 species [14]. Moreover, $\mathrm{T}$ lineage in 


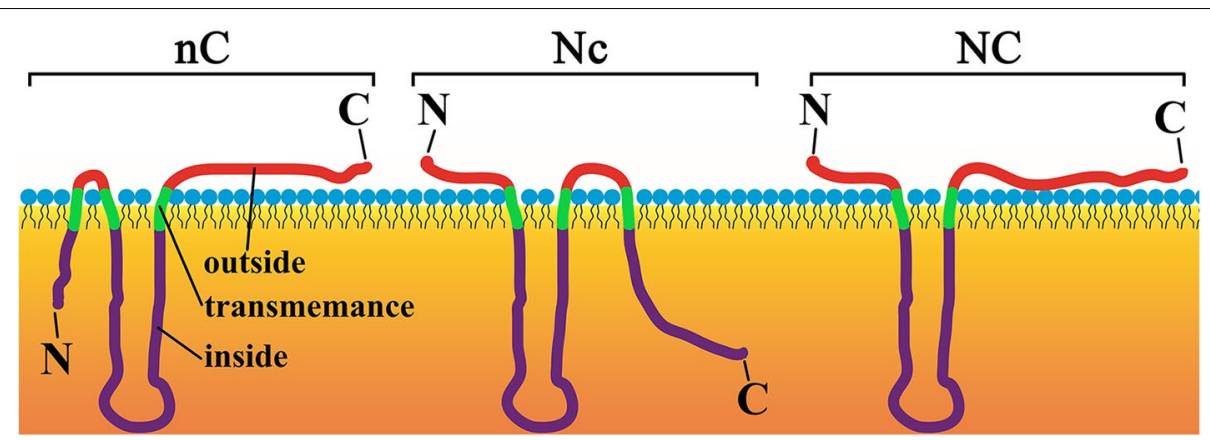

Fig. 8 The transmembrane models of transmembrane helices in GhOLEO proteins. nC, N-terminus inside and C-terminus outside; Nc, N-terminus outside and C-terminus inside; NC, both N-terminus and C-terminus outside

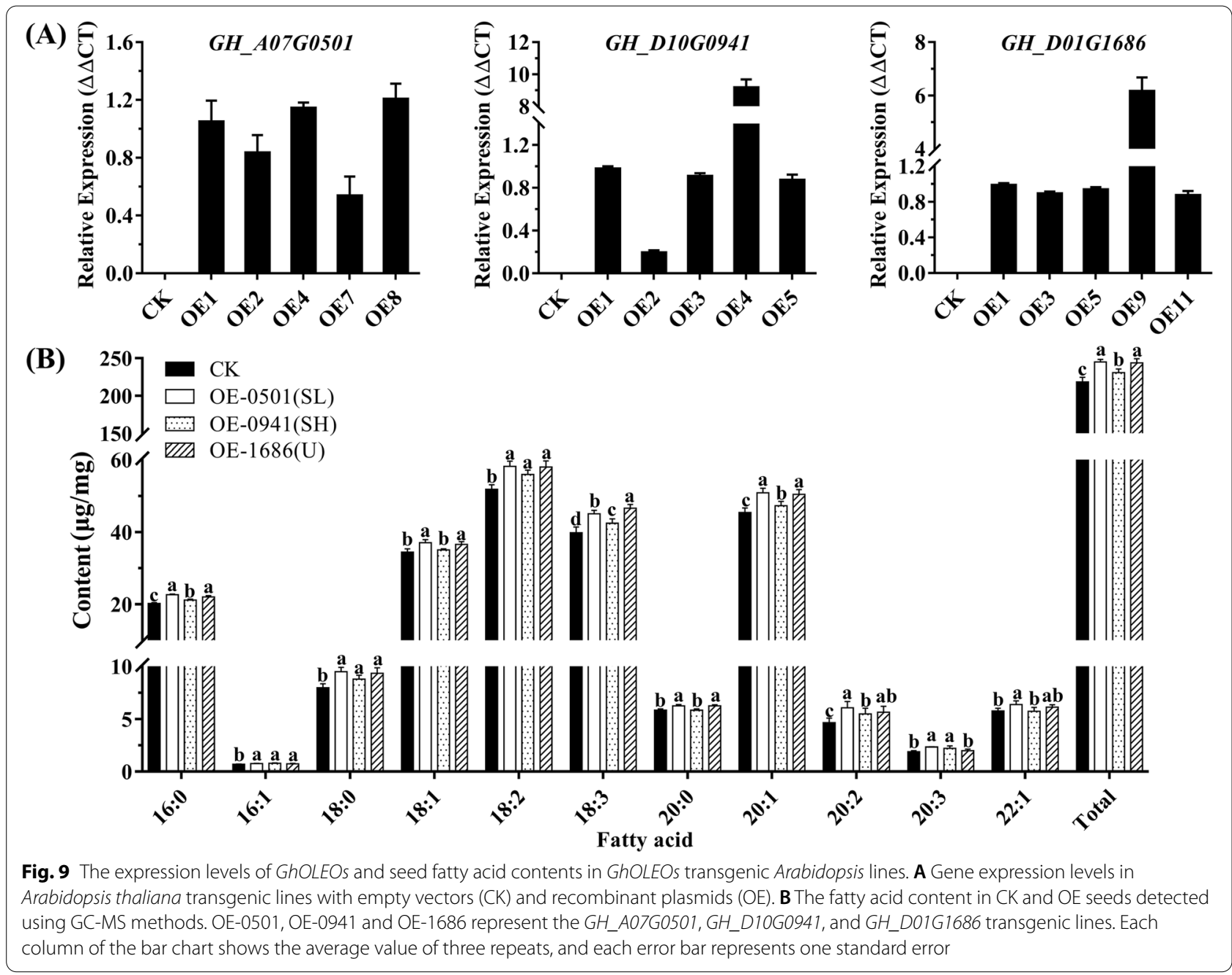

the terrestrial lineages ( $\mathrm{T}, \mathrm{U}, \mathrm{SL}$, and $\mathrm{SH})$ existed only in Tapeta. The cotton OLEOs were divided into U, SL, and $\mathrm{SH}$ lineages, according to the $O L E O$ phylogenetic tree combing A. thaliana, B. napus, and four cotton species (Fig. 1). For the number of OLEOs in each lineage, each tetraploid cotton had nearly twice as many as each diploid cotton, and the OLEOs of tetraploid corresponded to OLEOs of diploid one by one and were clustered together at the end branches of the evolutionary tree. These results also indicated that the $O L E O$ gene families of the 
Table 1 The fatty acid contents (ug/mg) in GhOLEOs transgenic Arabidopsis seeds

\begin{tabular}{|c|c|c|c|c|c|c|c|}
\hline \multirow[t]{2}{*}{ Fatty acid } & \multirow{2}{*}{$\begin{array}{l}\text { CK } \\
\text { Mean }\end{array}$} & \multicolumn{2}{|c|}{ OE-0501(SL) } & \multicolumn{2}{|c|}{ OE-0941(SH) } & \multicolumn{2}{|c|}{ OE-1686(U) } \\
\hline & & Mean & Incremental & Mean & Incremental & Mean & Incremental \\
\hline $16: 0$ & 20.20 & 22.64 & 2.44 & 21.14 & 0.95 & 22.04 & 1.84 \\
\hline $16: 1$ & 0.70 & 0.76 & 0.06 & 0.77 & 0.08 & 0.74 & 0.05 \\
\hline $18: 0$ & 7.97 & 9.50 & 1.53 & 8.79 & 0.82 & 9.34 & 1.37 \\
\hline $18: 1$ & 34.41 & 37.00 & 2.59 & 35.01 & 0.60 & 36.55 & 2.13 \\
\hline $18: 2$ & 51.80 & 58.16 & 6.37 & 55.92 & 4.12 & 58.00 & 6.20 \\
\hline $18: 3$ & 39.84 & 45.01 & 5.17 & 42.44 & 2.60 & 46.60 & 6.76 \\
\hline $20: 0$ & 5.83 & 6.24 & 0.41 & 5.84 & 0.01 & 6.24 & 0.41 \\
\hline $20: 1$ & 45.38 & 50.81 & 5.44 & 47.23 & 1.86 & 50.44 & 5.06 \\
\hline $20: 2$ & 4.64 & 6.05 & 1.41 & 5.48 & 0.84 & 5.65 & 1.01 \\
\hline $20: 3$ & 1.89 & 2.33 & 0.45 & 2.20 & 0.32 & 1.98 & 0.09 \\
\hline $22: 1$ & 5.77 & 6.37 & 0.60 & 5.72 & -0.04 & 6.13 & 0.36 \\
\hline Saturated & 34.00 & 38.38 & 4.38 & 35.77 & 1.78 & 37.62 & 3.63 \\
\hline Monounsaturated & 86.25 & 94.94 & 8.69 & 88.74 & 2.49 & 93.85 & 7.60 \\
\hline Polyunsaturated & 98.17 & 111.56 & 13.39 & 106.04 & 7.88 & 112.24 & 14.07 \\
\hline unsaturated & 184.41 & 206.50 & 22.08 & 194.78 & 10.37 & 206.09 & 21.67 \\
\hline Total & 218.41 & 244.88 & 26.47 & 230.55 & 12.14 & 243.71 & 25.30 \\
\hline
\end{tabular}

Incremental indicates the increased contents of fatty acids compared to the control group

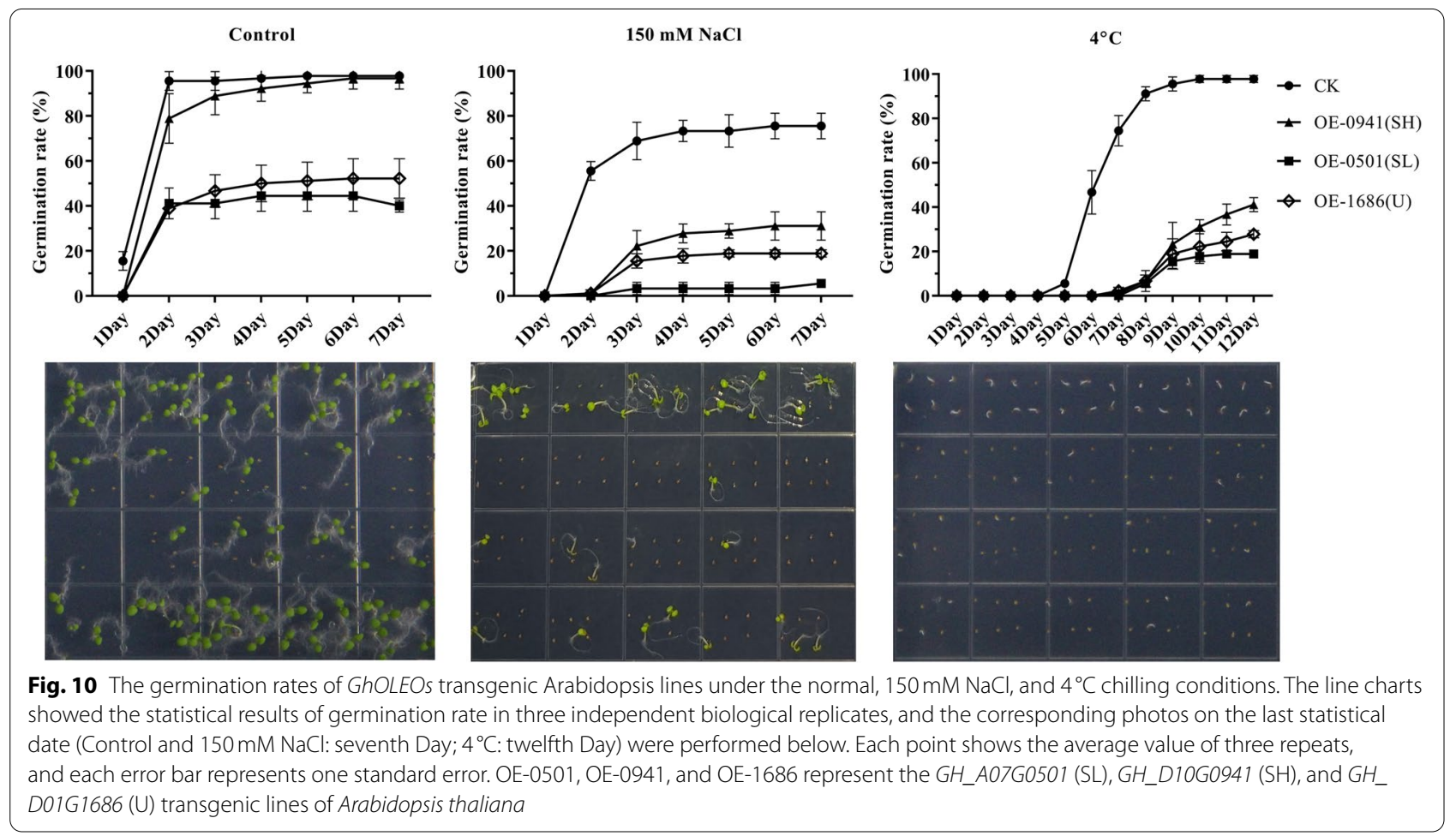

A- and D-genome in diploids combined and formed the AD gene family in neoallopolyploids, which occured during the polyploidization of two diploid cotton species to form the allopolyploid cotton approximately 1.7-1.9 million years ago [53].
Studying the gene structure is necessary to identifying gene evolution. In the present study, motif 1 containing proline junction $\left(\mathrm{PX}_{5} \mathrm{SPX}_{3} \mathrm{P}\right)$ was common to all OLEO genes except $G B_{-} A 09 G 0715$, which also had a proline junction. The proline junction $\left(\mathrm{PX}_{5} \mathrm{SPX}_{3} \mathrm{P}\right)$ was the loop 
of the highly conserved hairpin structure, which penetrates into the core of the oil body and plays an essential role in targeting and stabilizing the oil body [18]. In contrast, some conserved motifs are specific to subfamilies in oleosin proteins of cotton. The specific conserved motifs and gene structure possibly resulted in functional differences of OLEOs in different evolutionary tree lineages. For instance, motifs $7,12,13,16,20,22$, and 23 were specific to SH OLEOs, which might lead to conserved and specific functions in these genes. Gene duplication is the main driver of evolution, increasing the gene number and leading to functional differentiation for adapting to environmental changes [60]. In this study, all OLEOs in tetraploid kinds of cotton and most OLEOs in diploids were replicated through WGD or segmental duplications, while several OLEOs of diploid kinds of cotton were dispersed duplicated (Table S3).

MiRNAs, 19-24 bp length non-coding RNAs widespread in plants, animals, and viruses, play significant roles in post-transcriptional regulation. Likewise, they also significantly contributed to plant developments, including fatty acid biosynthesis [61]. For dissecting the regulation of GhOLEO expression, 24 candidate miRNAs targeting the GhOLEOs were predicted using the psRNATarget server (Fig. 4), and 12 of them belonged to 10 verified miRNA families, including ghr-miR159, ghr-miR160, ghr-miR168, ghr-miR3627, ghr-miR418, ghr-miR479, ghrmiR482, ghr-miR7507, ghr-miR825, and ghr-miR8672. Studies have shown that miR159 plays important roles in fatty acid biosynthesis during seed development in sea buckthorn, soybean, rice, Brassica napus, Arabidopsis [62-66]. Also, miR160 significantly affected seed development in A. thaliana [67]. The identification of ghr-miRNA genes and their targets broadens our understanding of the regulatory mechanism of GhOLEOs involved in cotton fatty acid biosynthesis.

Oleosins were proved to be the main structural proteins in the oil bodies, which have a core of neutral lipids surrounded by the phospholipid monolayer [4, 6]. In cotton, the oleosins were predicted to bind to plasmamembrane (Table S1). Moreover, the subcellular localization of GH_D01G1686:GFP, GH_A07G0501:GFP, GH_D10G0941:GFP, and GFP proteins showed the SL, $\mathrm{SH}$, and $\mathrm{U}$ oleosins were anchored to the oil body membrane (Fig. 7), which was consistent with previous results. To further understand the mode in which the oleosins bind to the membrane, the transmembrane helices of all GhOLEO proteins were analyzed using web-server TMHMM 2.0. And, all the transmembrane helices characters were observed and summarized into three transmembrane models, consist of $\mathrm{nC}$, Nc, and NC (Fig. 8, Fig. S3, Fig. S4, and Fig. S5). It was found that the SH oleosins were $\mathrm{nC}$ or Nc models, in which three transmembrane helices existed, and only one terminus was outside to the cytoplasm (Fig. 8 and Fig. S3). In addition, all the SL oleosins were NC models, whose both $\mathrm{N}$ - and C-terminus were outside, while the $\mathrm{U}$ oleosins contained all the three models (Fig. S4 and Fig. S5). However, only the NC model, both $\mathrm{N}$-terminus and $\mathrm{C}$-terminus outside, was reported in previous researches $[14,15,20]$. These three speculated models, especially the newly proposed $\mathrm{nC}$ and Nc models, should be verified experimentally and might provide a reference for the further study of gene function.

Previous studies have shown that oleosins contribute significantly to the formation of oil bodies and the accumulation of lipids $[7,17,28,31])$. In this research, the contribution of $S L-, S H-$, and $U-O L E O s$ to lipid accumulation in seeds were investigated with overexpressing GhOLEOs in Arabidopsis. As shown in Fig. 9, all the fatty acid components were increased in Arabidopsis seeds with overexpression of $\mathrm{SL}, \mathrm{SH}$, or U GhOLEOs. Although previous results showed that the fatty acid or oleosins could increase the stress resistance of seeds [68], the overexpression of GhOLEOs in Arabidopsis leaded to a low germination rate and resistance of seeds under normal, salt, or chilling condition (Fig. 10). The oleosins, no matter $\mathrm{SH}, \mathrm{SL}$, and $\mathrm{U}$, play an essential role in maintaining the stability of the oil body $[21,69]$. Their degradation is involved in lipids release from oil bodies during germination $[70,71]$. The increase of oleosins might enhance the binding force of the oil body on lipids, and the lipid mobilization became harder. The overexpression of oleosin decreased the size of the oil body and increase the content of lipids in seeds [31,33], while the loss of oleosin led to bigger oil bodies and lower lipid content in seeds [7, 32]. Furthermore, the oil body size was partly controlled by the ratio of lipid to oleosin proteins [72]. So, the oleosin was indispensable but not too much. Thus, the germination and stress resistance of seeds with higher oleosin levels became lower in this study. In addition, the co-expression of oleosin with lipid synthesis genes, such as DGAT, WRI1, and FAD, could further improve the oil content in seeds $[17,73]$. And, this method might recover the ratio of lipid to oleosin and the oil body size compared with the seeds of transgenic lines that only expressed the single gene $O L E O$. These results might provide a foundation or reference for the development of cultivars with high oil and improvement of the lipid content in cotton seeds.

\section{Conclusions}

In this research, 25 GhOLEOs, 24 GbOLEOs, $12 \mathrm{GaO}$ $L E O s$, and 13 GrOLEOs were identified and clustered into three lineages according to the phylogenetic tree. Then, their chromosomal location, gene structure, conserved motifs, conserved domains, and collinearity and 
duplication were analyzed for understanding the gene family expansion and gene evolution. Synteny analysis revealed that most of the oleosin genes were conserved, and their expansion might be mainly driven by WGD or segmental duplications. With bioinformatics tools, 24 candidate miRNAs targeting GhOLEOs were obtained, and the miRNA-GhOLEO regulatory network was constructed. The transmembrane helices in GhOLEO proteins were predicted, and three transmembrane models were summarized. In addition, the expressions of GhOLEO in different tissues and developmental stage ovules were performed and confirmed using qRT-PCR, implying that GhOLEOs might be involved in oil accumulation. Furthermore, their functions involved in oil accumulation and germination of seeds were identified with overexpressed in Arabidopsis and calculating germination rate of transgenic seeds under normal, salt, and chilling conditions. Take together, these findings provide insight into the potential functional roles of the GhOLEO genes and will help to improve the seed oil content of $G$. hirsutum.

\section{Methods}

\section{Plant materials and sequence retrieval}

The 1-25 dpa (days post-anthesis) ovules of 'Han682' cotton (G. hirsutum) plants, originally cultivated by Handan Academy of Agricultural Sciences, were harvested from the experimental field of Shandong Agricultural University [74]. The samples were immediately frozen in liquid nitrogen and stored at $-80^{\circ} \mathrm{C}$. These plant materials sampled for experimental research required no permissions. Experimental research on plants in this study, including the collection of plant material, comply with institutional, national, or international guidelines and the Convention on the Trade in Endangered Species of Wild Fauna and Flora.

The genome files and annotation gff3 files of G. hirsutum (ZJU, TM-1), G. barbadense (ZJU, H7124), G. arboreum (CRI, Shiyaxi1), and G. raimondii (JGI) were downloaded from the Cottongen database (https:// www.cottongen.org). The OLEO protein sequences of Arabidopsis thaliana [75] and Brassica napus [17] were obtained from the EnsemblPlants database (http://plants. ensembl.org/Brassica_napus/Info/Index) and TAIR database (http://www.arabidopsis.org/index.jsp), respectively.

\section{Genome-wide identification and properties analysis of Oleosin genes}

Firstly, all the $17 \mathrm{~A}$. thaliana OLEO proteins and $48 \mathrm{~B}$. napus OLEO proteins were used as query sequences to scan the whole genome protein sequences of four cotton species with BLASP search (e-value <1e-5). Secondly, the Hidden Markov Model (HMM) profile of the Oleosin domain (PF01277), acquired from the Pfam database (http://pfam.xfam.org/), was used in HMM search to identify $O L E O$ genes. The conversed protein sequence of oleosins with e-value $<1 \mathrm{e}-15$ were aligned using ClustalW and used to construct the new HMM profile for each cotton species. The species-specific HMM profiles were then employed to detect possible oleosins in each cotton species. Finally, all the non-redundant protein sequences, from the results of BLASTP and HMM search, were further identified using the NCBI Conserved Domain Database (CDD, https://www.ncbi.nlm.nih.gov/ cdd) with the automatic model and default parameters (threshold $=0.01$, maximum hits $=500$ ).

The information about all oleosins, including physical location, strand, length, coding sequence (CDS) length, exon number, the number of amino acids (NNA), molecular weight $(\mathrm{Mw})$, charge, isoelectric point $(\mathrm{pI})$, and grand average of hydropathy (GRAVY) were fetched with feature analysis in CottonFGD database. The chromosome localization of OLEO genes was drawn using TBtools [76] with the genome annotation gff3 files.

\section{Duplication and synteny analysis of Oleosin genes}

Firstly, the whole genome protein sequences of the four cotton species were pairwise compared using BLAST. Then, the synteny examination of paralogous genes in four cotton species was calculated with MCScanX (http://chibba.pgml.uga.edu/duplication/) in TBtools. Afterward, synteny visualization was conducted using TBtools.

\section{Phylogenetic analysis of Oleosin genes}

The phylogenetic tree was constructed with Mega X [77] as follows: the protein sequences were aligned using ClustalW with default parameters; after that, the Maximum Likelihood tree was built with the Poisson model, and 1000 replicates bootstrap. The tree was colored in web-server ITOL (https://itol.embl.de/).

\section{Gene structure and conserved motif analysis}

Gene Structure Display Server 2.0 (GSDS, http://gsds.cbi. pku.edu.cn/) was employed to analyze the exon-intron structures of the OLEO genes. And, the conserved motifs of the oleosins were detected using MEME v5.1.0 (http:// meme-suite.org/tools/meme) with parameters as follow: zoop (zero or one occurrence per sequence) was selected in site distribution, the width of motifs was 6 to 50, and the maximum number of motifs was set as 24 . The visualization of all the characteristic results was constructed and merged in TBtools. 


\section{Prediction of miRNA targeting GhOLEO genes}

The miRNAs targeting GhOLEO genes were predicted by querying their full coding sequences against the miRNA databases in web-server PMRD (plant microRNA database, https://bioinformatics.cau.edu.cn/PMRD/), miRbase (http://www.mirbase.org/), and psRNATarget (http://plantgrn.noble.org/psRNATarget/analysis?funct ion=2), and the non-redundant miRNAs identified in published papers (Table S6 [45-52];). The default parameters used were modified with the maximum expectation to 4.5. GhOLEOs-miRNAs interaction networks were illustrated using the Cytoscape 3.7.0 software [78].

\section{Expression analysis of Oleosin genes}

Based on the gene expression database of TM-1 and H7124 [53], the expression profiles of OLEOs in root, stem, leaf, and ovules $(0,1,3,5,10,20 \mathrm{dpa})$ were obtained and analyzed. The expression of OLEOs was displayed in the heatmap after normalized with $\log _{2}(\mathrm{FPKM}+1)$. Furthermore, the expressions of GhOLEO genes were checked with qRT-PCR of $1,3,5,10,20$, and 25 dpa 'Han682' ovules. The total RNA was extracted with an OminiPlant RNA Kit (DNase I) (CWBIO). A $20-\mu \mathrm{L}$ reaction volume containing $1 \mu \mathrm{g}$ of total RNA was used to synthesize template cDNA with a HiFiScript cDNA Synthesis Kit (CWBIO). In the qRT-PCR, UBQ7 was used as an internal reference, and the Applied Biosystems 7500 Real-Time PCR System was employed. Each reaction was performed at least three times, and relative expressions were analyzed with the $\Delta \Delta \mathrm{Ct}$ method. All the qRT-PCR primers were shown in Table S8.

\section{Subcellular localization and overexpression of GhOLEOs}

The subcellular localization of all OLEOs in four cotton species was predicted in the web-server CELLO v2.5 (http://cello.life.nctu.edu.tw/). For experimental verification of these predicted results, the non-terminator coding sequences of three GhOLEOs in $\mathrm{SL}, \mathrm{SH}$, and $\mathrm{U}$ lineages were cloned from cDNA of Han682, which was cultivated by Handan Academy of Agricultural Sciences, and fused to a green fluorescent protein (GFP) into vector pBI121 for subcellular localization. The specific primers were listed in Table S8. The recombinant plasmid and the control pBI121-35S::GFP Agrobacterium tumefaciens (EHA105) cells were injected into Nicotiana benthamiana leaves (4weeks old). After being cultured in dark overnight and $16 \mathrm{~h}$ light $/ 8 \mathrm{~h}$ dark photoperiod $2 \mathrm{~d}$, the leaves selected were incubated in the Nile red for $15 \mathrm{~min}$ and washed in water for $5 \mathrm{~min}$ before scanning. Then, the leaves were observed and photographed with an Agilent TCSsp5IIconfocal laser scanning microscope. GFP was excited with the $488 \mathrm{~nm}$ line of an argon laser and the
Nile red with a $633 \mathrm{~nm}$ neon laser. The detection of GFP and Nile Red emission was performed in a sequential line-scanning mode with $495-510 \mathrm{~nm}$ and $637-650 \mathrm{~nm}$, respectively. The subcellular localization of GhOLEOs was observed by combing CLSM and bright-field microscopy. Prediction of transmembrane helices in proteins was completed in TMHMM Server v. 2.0 (http://www. cbs.dtu.dk/services/TMHMM/).

In addition, the full coding sequences of GhOLEO genes were cloned into vector pCAMbia2300 with the $35 \mathrm{~S}$ promoter, respectively, for gene overexpression. The specific primers were listed in Table S8. The reconstructed plasmids and empty vectors above were introduced into A. tumefaciens (EHA105), respectively. Then, the plasmids were transformed into $A$. thaliana wild-type (Col-0, WT) plants using the floral dip method [79]. The empty vector transgenic lines were used as control (CK).

\section{Seed oil content determination}

The washed seeds $(10 \mathrm{mg})$ were placed into a glass tube containing $1.5 \mathrm{~mL}$ of $2.5 \%$ sulfuric acid-methanol solution, $0.3 \mu \mathrm{g}$ of butylated hydroxytoluene, and $0.25 \mathrm{~mL}$ of toluene. Then, $0.1 \mathrm{~mL}$ of C19:0 in toluene $(2.2 \mathrm{mg} / \mathrm{mL})$ was added to the tube as a standard internal substance. After vortexed, the mixture was heated in water at $90^{\circ} \mathrm{C}$ for $1 \mathrm{~h}$ and then cooled. The solution was left to stand overnight after adding $1.6 \mathrm{~mL}$ of $\mathrm{dd}_{2} \mathrm{O}$ and $1 \mathrm{~mL}$ of hexane. Afterward, the supernatant was filtered using a $0.45-\mu \mathrm{m}$ microporous membrane. Then $1 \mathrm{~mL}$ filtrate was used to detect the oil content by GC-MS. The parameters for GC-MS were as follows: an Agilent 7890A-88HPINNOWAX column $(100 \mathrm{~m} \times 0.25 \mathrm{~mm} \times 0.25 \mathrm{~mm})$ was employed; the flow rate of Helium (carrier gas) was kept at $1 \mathrm{~mL} / \mathrm{min}$; the column temperature was held at $120^{\circ} \mathrm{C}$ for $5 \mathrm{~min}$ firstly, and then raised to $240^{\circ} \mathrm{C}$ with $3.5^{\circ} \mathrm{C} / \mathrm{min}$ and maintained for $10 \mathrm{~min}$; the interface temperature of GC-MS was set to $250^{\circ} \mathrm{C}$, the ion source temperature was at $230^{\circ} \mathrm{C}$ and $\mathrm{EI}$ ionization at $70 \mathrm{eV}$.

\section{Salt /chilling tolerance assessment}

For germination assessment, the Arabidopsis (Col-0) seeds were sterilized and then sown on 1/2 Murashige and Skoog (MS) medium containing $0 \mathrm{mM} \mathrm{NaCl}$ (Control, CT) or $150 \mathrm{mM} \mathrm{NaCl}$ ( $\mathrm{NaCl}$ treatment). After vernalization for $4 \mathrm{~d}$ at $4^{\circ} \mathrm{C}$ and darkness, the plates were cultured at $22^{\circ} \mathrm{C}$ and $12 \mathrm{~h}$ light $/ 12 \mathrm{~h}$ dark. Simultaneously, some plates without $\mathrm{NaCl}$ were placed at $4{ }^{\circ} \mathrm{C}$ and $12 \mathrm{~h}$ light $/ 12 \mathrm{~h}$ dark (marked as Chilling treatment). The germinated seeds (CT and $\mathrm{NaCl}$ treatment) were counted on 1-7th day after sowing for salt tolerance assessment. CT and Chilling treatment were counted on the 1-12th day after planting for chilling tolerance assessment. 


\section{Statistical analysis of data}

For the accuracy of the experiment, data detection and measurement were repeated more than three times in this study. Finally, the mean values and the standard deviations of repeats were presented.

\section{Abbreviations}

OLEO: Oleosin; TAGs: Triacylglycerols; OBs: Oil bodies; ER: Endoplasmic reticulum; M: Mesocarp lineage; T: Tapetum lineage; P: Primitive lineage; U: Universal lineage; SL: Seed low-molecular-weight lineage; SH: Seed high-molecularweight lineage; GR: Germination rate; NAA: The number of amino acids; Mw: Molecular weight; pl: Isoelectric point; WGD: Whole-genome duplications; HMM: Hidden Markov Model; CDD: Conserved domain database; GRAVY: Grand average of hydropathy.

\section{Supplementary Information}

The online version contains supplementary material available at https://doi. org/10.1186/s12870-021-03358-y.

Additional file 1: Figure S1 Chromosome distribution of Oleosin genes in four cotton species. Figure $\mathbf{S 2}$ Collinearity analyses of Oleosin genes between G. hirsutum, G. barbadense, G. arboretum, and G. raimondii. Figure S3 The prediction of transmembrane helices in SH GhOLEO proteins. nC, $\mathrm{N}$-terminus inside and C-terminus outside; Nc, N-terminus outside and C-terminus inside. Figure S4 The prediction of transmembrane helices in SL GhOLEO proteins. NC, both N-terminus and C-terminus outside. Figure S5 The prediction of transmembrane helices in U GhOLEO proteins. $\mathrm{nC}$, $\mathrm{N}$-terminus inside and $\mathrm{C}$-terminus outside; $\mathrm{Nc}$, N-terminus outside and C-terminus inside; NC, both N-terminus and C-terminus outside.

Additional file 2: Table $\mathbf{S 1}$ The sequence properties of Oleosin genes identified in four cotton species. Table S2 The homologous Oleosin genes among four cotton species. Table S3 Duplicated Oleosin gene pairs in each cotton species. Table S4 Information of motifs in Oleosin genes. Table S5 Details for predicted miRNA targeting GhOLEOs. Table S6 The non-redundant published miRNAs used in this study. Table S7 The expression profiles (FPKM) of OLEOs in root, stem, leaf, and 0-20 ovules [53]. Table S8 Specific primers for qRT-PCR or vector constructions.

\section{Acknowledgements}

Not applicable.

\section{Authors' contributions}

S.G. and XL.S.: Conceptualization, Methodology, Software. Y.Y.: Data curation, Writing-Original draft preparation, visualization. X.C.: Visualization, Investigation. H.Z.: Software, Validation. C.L. and Y.Z.: Reviewing and Editing. All authors have read and approved the manuscript.

\section{Funding}

This work was mainly supported by the Shandong Provincial Natural Science Foundation [ZR2020QC160]. Agricultural Seed Projects of Shandong Province [2020LZGC002] and Modern Agro-industry Technology Research System of Shandong Province [SDAIT-03-03/05] supported the cotton materials and the gene clone. Research Fund of Qingdao Agricultural University's Highlevel Person [663/1120077] contributed to the seed oil determination and salt / chilling tolerance assessment.

\section{Availability of data and materials}

The genome files and annotation gff3 files of G. hirsutum (ZJU, TM-1), G. barbadense (ZJU, H7124), G. arboreum (CRI, Shiyaxi1), and G. raimondii (JGI) were downloaded from the Cottongen database (https://www.cottongen. org). The OLEO protein sequences of Arabidopsis thaliana and Brassica napus were obtained from the EnsemblPlants database (http://plants.ensembl.org/ Brassica_napus/Info/Index) and TAIR database (http://www.arabidopsis.org/ index.jsp), respectively.
Experimental research on plants in this study complies with institutional, national, or international guidelines and the Convention on the Trade in Endangered Species of Wild Fauna and Flora.

\section{Declarations}

Ethics approval and consent to participate

Not applicable.

Consent for publication

Not applicable.

\section{Competing interests}

The authors declare that they have no competing interests.

Received: 1 June 2021 Accepted: 24 November 2021

Published online: 04 December 2021

\section{References}

1. Yang HK, Zhang XY, Chen BL, Meng YL, Zhao WQ, Wang YH, et al. Integrated soil-cotton system management enhances triacylglycerol yield and favourable fatty acid profile. Ind Crop Prod. 2018;117:393-403. https://doi.org/10.1016/j.indcrop.2018.03.023.

2. Yuan $Y$, Wang $X$, Wang $L$, Xing $H$, Wang Q, Saeed $M$, et al. Genome-wide association study identifies candidate genes related to seed oil composition and protein content in Gossypium hirsutum L. Front Plant Sci. 2018:9:1359. https://doi.org/10.3389/fpls.2018.01359.

3. Deruyffelaere C, Purkrtova Z, Bouchez I, Collet B, Cacas JL, Chardot T, et al. PUX10 is a CDC48A adaptor protein that regulates the extraction of ubiquitinated oleosins from seed lipid droplets in Arabidopsis. Plant Cell. 2018:30(9):2116-36. https://doi.org/10.1105/tpc.18.00275.

4. Huang $\mathrm{AH}$. Oleosins and oil bodies in seeds and other organs. Plant Physiol. 1996;110(4):1055-61. https://doi.org/10.1104/pp.110.4.1055.

5. Murphy DJ. The biogenesis and functions of lipid bodies in animals, plants and microorganisms. Prog Lipid Res. 2001;40(5):325-438. https:// doi.org/10.1016/s0163-7827(01)00013-3.

6. Shimada TL, Hara-Nishimura I. Oil-body-membrane proteins and their physiological functions in plants. Biol Pharm Bull. 2010;33(3):360-3. https://doi.org/10.1248/bpb.33.360.

7. Siloto RM, Findlay K, Lopez-Villalobos A, Yeung EC, Nykiforuk CL, Moloney MM. The accumulation of oleosins determines the size of seed oilbodies in Arabidopsis. Plant Cell. 2006;18(8):1961-74. https://doi.org/10.1105/ tpc.106.041269

8. Vance $V B$, Huang $\mathrm{AH}$. The major protein from lipid bodies of maize. Characterization and structure based on cDNA cloning. J Biol Chem. 1987:262(23):11275-9.

9. Keddie JS, Hubner G, Slocombe SP, Jarvis RP, Cummins I, Edwards EW et al. Cloning and characterisation of an oleosin gene from Brassica napus. Plant Mol Biol. 1992;19(3):443-53. https://doi.org/10.1007/BF000 23392.

10. Chen JC, Lin RH, Huang HC, Tzen JT. Cloning, expression and isoform classification of a minor oleosin in sesame oil bodies. J Biochem. 1997;122(4):819-24. https://doi.org/10.1093/oxfordjournals.jbchem.a0218 28.

11. Sarmiento C, Ross JH, Herman E, Murphy DJ. Expression and subcellular targeting of a soybean oleosin in transgenic rapeseed. Implications for the mechanism of oil-body formation in seeds. Plant J. 1997;11(4):783-96. https://doi.org/10.1046/j.1365-313x.1997.11040783.x.

12. Wu LS, Wang LD, Chen PW, Chen LJ, Tzen JT. Genomic cloning of 18 kDa oleosin and detection of triacylglycerols and oleosin isoforms in maturing rice and postgerminative seedlings. J Biochem. 1998;123(3):386-91. https://doi.org/10.1093/oxfordjournals.jbchem.a021949.

13. Alexander LG, Sessions RB, Clarke AR, Tatham AS, Shewry PR, Napier JA. Characterization and modelling of the hydrophobic domain of a sunflower oleosin. Planta. 2002;214(4):546-51. https://doi.org/10.1007/s0042 50100655.

14. Huang MD, Huang AHC. Bioinformatics reveal five lineages of oleosins and the mechanism of lineage evolution related to structure/function 
from green algae to seed plants. Plant Physiol. 2015;169(1):453-70. https://doi.org/10.1104/pp.15.00634.

15. Huang AH. Plant lipid droplets and their associated proteins: potential for rapid advances. Plant Physiol. 2018;176(3):1894-918.

16. Huang CY, Chen PY, Huang MD, Tsou CH, Jane WN, Huang AH. Tandem oleosin genes in a cluster acquired in Brassicaceae created tapetosomes and conferred additive benefit of pollen vigor. Proc Natl Acad Sci U S A. 2013;110(35):14480-5. https://doi.org/10.1073/pnas.1305299110.

17. Chen K, Yin Y, Liu S, Guo Z, Zhang K, Liang Y, et al. Genome-wide identification and functional analysis of oleosin genes in Brassica napus L. BMC Plant Biol. 2019;19(1):294. https://doi.org/10.1 186/s12870-019-1891-y.

18. Wu Y-Y, Chou Y-R, Wang C-S, Tseng T-H, Chen L-J, Tzen JT. Different effects on triacylglycerol packaging to oil bodies in transgenic rice seeds by specifically eliminating one of their two oleosin isoforms. Plant Physiol Biochem. 2010;48(2-3):81-9.

19. Abell BM, Holbrook LA, Abenes M, Murphy DJ, Hills MJ, Moloney MM. Role of the proline knot motif in oleosin endoplasmic reticulum topology and oil body targeting. Plant Cell. 1997;9(8):1481-93.

20. Baud S, Lepiniec L. Physiological and developmental regulation of seed oil production. Prog Lipid Res. 2010;49(3):235-49.

21. Huang $C Y$, Huang AHC. Unique motifs and length of hairpin in oleosin target the cytosolic side of endoplasmic reticulum and budding lipid droplet. Plant Physiol. 2017;174(4):2248-60. https://doi.org/10.1104/pp. 17.00366.

22. Nikiforidis CV, Ampatzidis C, Lalou S, Scholten E, Karapantsios TD, Kiosseoglou V. Purified oleosins at air-water interfaces. Soft Matter. 2013;9(4):1354-63. https://doi.org/10.1039/c2sm27118d.

23. Ramachandiran I, Vijayakumar A, Ramya V, Rajasekharan R. Arabidopsis serine/threonine/tyrosine protein kinase phosphorylates oil body proteins that regulate oil content in the seeds. Sci Rep-Uk. 2018;8(1):1154.

24. Babazadeh N, Poursaadat M, Sadeghipour HR, Colagar AHZ. Oil body mobilization in sunflower seedlings is potentially regulated by thioredoxin h. Plant Physiol Biochem. 2012:57:134-42.

25. Krahmer N, Hilger M, Kory N, Wilfling F, Stoehr G, Mann M, et al. Protein correlation profiles identify lipid droplet proteins with high confidence. Mol Cell Proteomics. 2013;12(5):1115-26.

26. Hu Z, Wang X, Zhan G, Liu G, Hua W, Wang H. Unusually large oilbodies are highly correlated with lower oil content in Brassica napus. Plant Cell Rep. 2009;28(4):541-9.

27. Che N, Yang Y, Li Y, Wang L, Huang P, Gao Y, et al. Efficient LEC2 activation of OLEOSIN expression requires two neighboring RY elements on its promoter. Sci China C Life Sci. 2009;52(9):854-63. https://doi.org/10.1007/ s11427-009-0119-z.

28. Ha J, Shim S, Lee T, Kang YJ, Hwang WJ, Jeong H, et al. Genome sequence of Jatropha curcas L., a non-edible biodiesel plant, provides a resource to improve seed-related traits. Plant Biotechnol J. 2019;17(2):517-30.

29. Manan S, Ahmad MZ, Zhang G, Chen B, Haq BU, Yang J, et al. Soybean $\angle E C 2$ regulates subsets of genes involved in controlling the biosynthesis and catabolism of seed storage substances and seed development. Front Plant Sci. 2017;8:1604.

30. Song L, Fan C, Chen Y, Zhang X, Hu Z. The molecular regulation mechanism of the plant lipid biosynthesis. Mol Plant Breed. 2016;14:2178-87.

31. Zhang D, Zhang H, Hu Z, Chu S, Yu K, Lv L, et al. Artificial selection on GMOLEO1 contributes to the increase in seed oil during soybean domestication. PLoS Genet. 2019;15(7):e1008267.

32. Liu H, Wang X, Ren K, Li K, Wei M, Wang W, et al. Light deprivationinduced inhibition of chloroplast biogenesis does not arrest embryo morphogenesis but strongly reduces the accumulation of storage reserves during embryo maturation in Arabidopsis. Front Plant Sci. 2017:8:1287.

33. Miquel M, Trigui G, d'Andrea S, Kelemen Z, Baud S, Berger A, et al. Specialization of oleosins in oil body dynamics during seed development in Arabidopsis seeds. Plant Physiol. 2014;164(4):1866-78. https://doi.org/10. 1104/pp.113.233262.

34. Bhatla SC, KaushikV, Yadav MK. Use of oil bodies and oleosins in recombinant protein production and other biotechnological applications. Biotechnol Adv. 2010;28(3):293-300. https://doi.org/10.1016/j.biotechadv. 2010.01.001.

35. Cao H. Genome-wide analysis of oleosin gene family in 22 tree species: an accelerator for metabolic engineering of bioFuel crops and agrigenomics industrial applications? OMICS: I Integr Biol. 2015;19(9):521-41. https://doi.org/10.1089/omi.2015.0073.

36. Milioni D, Franz G, Sung R, Hatzopoulos P. Gene expression during heat-shock in embryogenic carrot cell lines. Plant Cell Tissue Org Cult. 2001;65:221-8.

37. Buchanan CD, Lim S, Salzman RA, Kagiampakis I, Morishige DT, Weers BD, et al. Sorghum bicolor's transcriptome response to dehydration, high salinity and ABA. Plant Mol Biol. 2005;58(5):699-720. https://doi.org/10. 1007/s11103-005-7876-2.

38. Huang G, Wu Z, Percy RG, Bai M, Li Y, Frelichowski JE, et al. Genome sequence of Gossypium herbaceum and genome updates of Gossypium arboreum and Gossypium hirsutum provide insights into cotton A-genome evolution. Nat Genet. 2020;52(5):516-24. https://doi.org/10. 1038/s41588-020-0607-4.

39. Liu X, Zhao B, Zheng HJ, Hu Y, Lu G, Yang CQ, et al. Gossypium barbadense genome sequence provides insight into the evolution of extra-long staple fiber and specialized metabolites. Sci Rep-Uk. 2015;5:14139. https:// doi.org/10.1038/srep14139.

40. Wendel JF. New World tetraploid cottons contain Old World cytoplasm. Proc Natl Acad Sci U S A. 1989;86(1 1):4132-6. https://doi.org/10.1073/ pnas.86.11.4132.

41. Zhang T, Hu Y, Jiang W, Fang L, Guan X, Chen J, et al. Sequencing of allotetraploid cotton (Gossypium hirsutum L. acc. TM-1) provides a resource for fiber improvement. Nat Biotechnol. 2015;33(5):531-7. https://doi.org/ 10.1038/nbt.3207.

42. Wendel JF, Cronn RC. Polyploidy and the evolutionary history of cotton. Adv Agron. 2003;78:139.

43. Chen Q, Chen QJ, Sun GQ, Zheng K, Yao ZP, Han YH, et al. Genomewide identification of Cyclophilin gene family in cotton and expression analysis of the fibre development in Gossypium barbadense. Int J Mol Sci. 2019;20(2). https://doi.org/10.3390/ijms20020349.

44. Wang W, Cheng Y, Chen D, Liu D, Hu M, Dong J, et al. The catalase gene family in cotton: genome-wide characterization and bioinformatics analysis. Cells. 2019;8(2). https://doi.org/10.3390/cells8020086.

45. Wang ZM, Xue W, Dong CJ, Jin LG, Bian SM, Wang C, et al. A comparative miRNAome analysis reveals seven fiber initiation-related and 36 novel miRNAs in developing cotton ovules. Mol Plant. 2012;5(4):889-900. https://doi.org/10.1093/mp/ssr094.

46. Chen J, Pan A, He S, Su P, Yuan X, Zhu S, et al. Different microRNA families involved in regulating high temperature stress response during cotton (Gossypium hirsutum L.) anther development. Int J Mol Sci. 2020;21 (4). https://doi.org/10.3390/ijms21041280.

47. Dong Z, Zhang J, Zhu Q, Zhao L, Sui S, Li Z, et al. Identification of microRNAs involved in drought stress responses in early-maturing cotton by high-throughput sequencing. Genes Genom. 2018;40(3):305-14. https:// doi.org/10.1007/s13258-017-0637-1.

48. Li J, Hull JJ, Liang S, Wang Q, Chen L, Zhang Q, et al. Genome-wide analysis of cotton miRNAs during whitefly infestation offers new insights into plant-herbivore interaction. Int J Mol Sci. 2019;20(21). https://doi.org/10. 3390/ijms20215357.

49. Xie F, Wang Q, Sun R, Zhang B. Deep sequencing reveals important roles of microRNAs in response to drought and salinity stress in cotton. J Exp Bot. 2015;66(3):789-804. https://doi.org/10.1093/jxb/eru437.

50. Yang X, Wang L, Yuan D, Lindsey K, Zhang X. Small RNA and degradome sequencing reveal complex miRNA regulation during cotton somatic embryogenesis. J Exp Bot. 2013;64(6):1521-36. https://doi.org/10.1093/ jxb/ert013.

51. Zhang Y, Wang W, Chen J, Liu J, Xia M, Shen F. Identification of miRNAs and their targets in cotton inoculated with Verticillium dahliae by high-throughput sequencing and degradome analysis. Int J Mol Sci. 2015;16(7):14749-68. https://doi.org/10.3390/ijms160714749.

52. Zhao T, Xu X, Wang M, Li C, Li C, Zhao R, et al. Identification and profiling of upland cotton microRNAs at fiber initiation stage under exogenous IAA application. BMC Genomics. 2019;20(1):421. https://doi.org/10.1186/ S12864-019-5760-8

53. Hu Y, Chen JD, Fang L, Zhang ZY, Ma W, Niu YC, et al. Gossypium barbadense and Gossypium hirsutum genomes provide insights into the origin and evolution of allotetraploid cotton. Nat Genet. 2019;51(4):739. https://doi.org/10.1038/s41588-019-0371-5.

54. Scott RW, Winichayakul S, Roldan M, Cookson R, Willingham M, Castle $M$, et al. Elevation of oil body integrity and emulsion stability by 
polyoleosins, multiple oleosin units joined in tandem head-to-tail fusions. Plant Biotechnol J. 2010;8(8):912-27. https://doi.org/10.1111/j.1467-7652. 2010.00522.x

55. Shimada TL, Shimada T, Takahashi H, Fukao Y, Hara-Nishimura I. A novel role for oleosins in freezing tolerance of oilseeds in Arabidopsis thaliana. Plant J. 2008;55(5):798-809. https://doi.org/10.1111/j.1365-313X.2008. 03553.x.

56. Simkin AJ, Qian T, Caillet V, Michoux F, Ben Amor M, Lin C, et al. Oleosin gene family of Coffea canephora: quantitative expression analysis of five oleosin genes in developing and germinating coffee grain. J Plant Physiol. 2006;163(7):691-708. https://doi.org/10.1016/j.jplph.2005.11.008.

57. Lu Y, Chi M, Li L, Li H, Noman M, Yang Y, et al. Genome-wide identification, expression profiling, and functional validation of Oleosin gene family in Carthamus tinctorius L. Front Plant Sci. 2018;9:1393. https://doi.org/10. 3389/fpls.2018.01393.

58. Du XM, Huang G, He SP, Yang ZE, Sun GF, Ma XF, et al. Resequencing of 243 diploid cotton accessions based on an updated a genome identifies the genetic basis of key agronomic traits. Nat Genet. 2018;50(6):796 https://doi.org/10.1038/s41588-018-0116-x.

59. Paterson AH, Wendel JF, Gundlach H, Guo H, Jenkins J, Jin D, et al. Repeated polyploidization of Gossypium genomes and the evolution of spinnable cotton fibres. Nature. 2012;492(7429):423-7. https://doi.org/10. 1038/nature11798.

60. Lynch M, Conery JS. The evolutionary fate and consequences of duplicate genes. Science. 2000;290(5494):1151-5. https://doi.org/10.1126/science. 290.5494.1151.

61. Xie F, Jones DC, Wang Q, Sun R, Zhang B. Small RNA sequencing identifies miRNA roles in ovule and fibre development. Plant Biotechnol J. 2015;13(3):355-69. https://doi.org/10.1111/pbi.12296.

62. Belide S, Petrie JR, Shrestha P, Singh SP. Modification of seed oil composition in Arabidopsis by artificial microRNA-mediated gene silencing. Front Plant Sci. 2012;3:168. https://doi.org/10.3389/fpls.2012.00168.

63. Ding J, Ruan C, Guan Y, Krishna P. Identification of microRNAs involved in lipid biosynthesis and seed size in developing sea buckthorn seeds using high-throughput sequencing. Sci Rep-Uk. 2018;8(1):4022. https://doi.org/ 10.1038/s41598-018-22464-w.

64. Peng T, Sun H, Qiao M, Zhao Y, Du Y, Zhang J, et al. Differentially expressed microRNA cohorts in seed development may contribute to poor grain filling of inferior spikelets in rice. BMC Plant Biol. 2014;14:196. https://doi. org/10.1186/s12870-014-0196-4

65. Song Q-X, Liu Y-F, Hu X-Y, Zhang W-K, Ma B, Chen S-Y, et al. Identification of miRNAs and their target genes in developing soybean seeds by deep sequencing. BMC Plant Biol. 2011;11(1). https://doi.org/10.1186/ 1471-2229-11-5.

66. Wang J, Jian H, Wang T, Wei L, Li J, Li C, et al. Identification of microRNAs actively involved in fatty acid biosynthesis in developing Brassica napus seeds using high-throughput sequencing. Front Plant Sci. 2016;7. https:// doi.org/10.3389/fpls.2016.01570.

67. Liu PP, Montgomery TA, Fahlgren N, Kasschau KD, Nonogaki H, Carrington JC. Repression of AUXIN RESPONSE FACTOR10 by microRNA160 is critical for seed germination and post-germination stages. Plant $J$. 2007;52(1):133-46. https://doi.org/10.1111/j.1365-313X.2007.03218.x.

68. Yang Y, Benning C. Functions of triacylglycerols during plant development and stress. Curr Opin Biotechnol. 2018;49:191-8. https://doi.org/10. 1016/j.copbio.2017.09.003.

69. Nikiforidis CV. Structure and functions of oleosomes (oil bodies). Adv Colloid Interf Sci. 2019:274:102039. https://doi.org/10.1016/j.cis.2019.102039.

70. Deruyffelaere C, Bouchez I, Morin H, Guillot A, Miquel M, Froissard M, et al. Ubiquitin-mediated proteasomal degradation of oleosins is involved in oil body mobilization during post-germinative seedling growth in Arabidopsis. Plant Cell Physiol. 2015;56(7):1374-87. https://doi.org/10.1093/ pcp/pcv056.

71. Parthibane V, Iyappan R, Vijayakumar A, Venkateshwari V, Rajasekharan R. Serine/threonine/tyrosine protein kinase phosphorylates oleosin, a regulator of lipid metabolic functions. Plant Physiol. 2012;159(1):95-104. https://doi.org/10.1104/pp.112.197194.

72. Frandsen Gl, Mundy J, Tzen JT. Oil bodies and their associated proteins, oleosin and caleosin. Physiol Plant. 2001;112(3):301-7. https://doi.org/10. 1034/j.1399-3054.2001.1120301.x.

73. Zulu NN, Popko J, Zienkiewicz K, Tarazona P, Herrfurth C, Feussner I. Heterologous co-expression of a yeast diacylglycerol acyltransferase
(SCDGA1) and a plant oleosin (AtOLEO3) as an efficient tool for enhancing triacylglycerol accumulation in the marine diatom Phaeodactylum tricornutum. Biotechnol Biofuels. 2017;10:187. https://doi.org/10.1186/ s13068-017-0874-1.

74. Yuan YC, Xing HX, Zeng WG, Xu JL, Mao LL, Wang LY, et al. Genome-wide association and differential expression analysis of salt tolerance in Gossypium hirsutum $L$ at the germination stage. BMC Plant Biol. 2019;19(1):394. https://doi.org/10.1186/s12870-019-1989-2.

75. Kim HU, Hsieh K, Ratnayake C, Huang AH. A novel group of oleosins is present inside the pollen of Arabidopsis. J Biol Chem. 2002;277(25):22677-84. https://doi.org/10.1074/jbc.M109298200.

76. Chen C, Chen H, Zhang Y, Thomas HR, Frank MH, He Y, et al. TBtools: an integrative toolkit developed for interactive analyses of big biological data. Mol Plant. 2020;13(8):1194-202. https://doi.org/10.1016/j.molp. 2020.06.009.

77. Kumar S, Stecher G, Li M, Knyaz C, Tamura K. MEGA X: molecular evolutionary genetics analysis across computing platforms. Mol Biol Evol. 2018;35(6):1547-9. https://doi.org/10.1093/molbev/msy096.

78. Shannon P, Markiel A, Ozier O, Baliga NS, Wang JT, Ramage D, et al. Cytoscape: a software environment for integrated models of biomolecular interaction networks. Genome Res. 2003;13(11):2498-504. https://doi. org/10.1101/gr.1239303.

79. Clough SJ, Bent AF. Floral dip: a simplified method for agrobacterium-mediated transformation of Arabidopsis thaliana. Plant J. 1998;16(6):735-43.

\section{Publisher's Note}

Springer Nature remains neutral with regard to jurisdictional claims in published maps and institutional affiliations.

Ready to submit your research? Choose BMC and benefit from:

- fast, convenient online submission

- thorough peer review by experienced researchers in your field

- rapid publication on acceptance

- support for research data, including large and complex data types

- gold Open Access which fosters wider collaboration and increased citations

- maximum visibility for your research: over $100 \mathrm{M}$ website views per year

At BMC, research is always in progress.

Learn more biomedcentral.com/submissions 